\title{
Belonging in STEM: Growth Mindset as a Filter of Contextual Cues
}

\author{
C. Lee Williams, Quinn Hirschi, Chris S. Hulleman, and Josipa Roksa \\ University of Virginia
}

Corresponding author: C. Lee Williams (email: clw8uk@virginia.edu; ORCID: 0000-00033433-1011)

This is a preprint of an article published in the International Journal of Community Well-Being.

The final authenticated version is available online at:

https://doi.org/10.1007/s42413-021-00111-z 


\begin{abstract}
Undergraduate students in science, technology, engineering, and mathematics (STEM) programs face unique challenges to their psychological well-being, including their sense of belonging. Recent evidence suggests that beliefs about the malleability of intelligence (growth mindsets) support STEM students' belongingness, though the mechanisms of this relationship are unclear. We propose and test a model in which students' personal growth mindset beliefs relate to their sense of belonging by operating as a filter of environmental cues, especially those signaling instructors' mindsets, peers' mindsets, and the overall trustworthiness of the school. Across more than 3,000 students in two diverse STEM contexts, we found general support for this model (mean RMSEA $=0.041$; mean $R^{2}=39 \%$ ). Perceived environmental cues explained 100\% (Study 1) and $35 \%$ (Study 2) of the total effect of personal growth mindset on belonging. In addition to model generalizability, there was meaningful heterogeneity in the results observed across contexts. These results suggest a novel filtering function of growth mindsets in addition to the importance of perceptions of instructors' growth mindsets and school trust for belonging. Discussion centers on the factors that may account for model variability, as well as theoretical and practical implications of the findings. Keywords: growth mindset; meta-growth mindset; school trust; belonging; STEM education
\end{abstract}




\section{Belonging in STEM: Growth Mindset as a Filter of Contextual Cues}

In the United States, there is a growing national priority to increase the number of individuals with science, technology, engineering, and mathematics (STEM) degrees in order to address a predicted shortfall of 2.4 million STEM workers by 2028 (Giffi, Wellener, Dollar, Ashton, Monck, \& Moutray, 2018; President's Council of Advisors on Science and Technology, 2012; Xue \& Larson, 2015). In service of this goal to increase the STEM workforce, most of the existing literature in postsecondary STEM contexts focuses on recruiting and retaining undergraduate STEM majors. Unfortunately, despite the well-documented threats to students' well-being in STEM (Casad, Petzel, \& Ingalls, 2019; Lipson, Zhou, Wagner, Beck, \& Eisenberg, 2016; Settles, O’Connor, \& Yap, 2016), and the importance of well-being to long-term adjustment and life success (Lyubomirsky, King, \& Diener, 2005), there has been very little attention to understanding and improving student psychological well-being in STEM programs. We address this gap by exploring the role of beliefs about the malleability of intelligence (i.e., growth mindset) and school trust in the development of a sense of belonging across two disparate postsecondary contexts.

Previously, researchers have treated growth mindset beliefs as a moderator of contextual factors that influence belonging (Good, Rattan, \& Dweck, 2012). In this view, holding a growth mindset (or perceiving one's environment to support a growth mindset) provides a psychological defense against group-based threats (e.g., stereotypes) that are activated by environmental cues. Although useful, this conceptualization does not account for the interplay between person and context; namely, how an individual's pre-existing beliefs may direct their perceptions of the environment. Mindsets may offer not only a buffer of threats already perceived, but also a lens to construe potential future sources of threat. In this paper, we develop and test a model of the relationship between personal growth mindset beliefs and belonging, in which the central focus 
is how individual beliefs may alter perceptions of the context. Specifically, we investigate how personal growth mindset beliefs may shape perceptions of context — which we operationalize as including peers' and instructors' mindset beliefs and institutional trust-which then inform a sense of belonging. In line with prior work on environmental threat, mindsets, and belonging in postsecondary STEM contexts (e.g., Cheryan, Drury, \& Vichayapai, 2013; Good et al., 2012), we explore moderation of the specified relationships by gender, a social identity group that faces persistent underrepresentation and stigmatization in STEM contexts.

\section{Belonging in Postsecondary STEM Contexts}

In higher education, a sense of belonging - the belief that one is accepted, respected, included, and supported by others (Goodenow \& Grady, 1993) — is an important aspect of wellbeing (Osterman, 2000; Slaten, Ferguson, Allen, Brodrick, \& Waters, 2016). Belonging has also been linked to important outcomes including interest (Thoman, Smith, Brown, Chase, \& Lee, 2013), persistence (Hausmann, Schofield, \& Woods, 2007), self-efficacy (Freeman, Anderman, \& Jensen, 2007), GPA (Han, Farruggia, \& Moss, 2017; Walton \& Cohen, 2007, 2011), depressive symptoms (Gummadam, Pittman, \& Ioffe, 2016), and self-worth (Pittman \& Richmond, 2007).

Belonging is particularly important in STEM fields (Strayhorn, 2019), which are often highly competitive, selective, and exclusionary. In addition to the stringent performance prerequisites that exclude students in general from STEM programs, students from underserved subgroups - including women and students from Black, Hispanic, and Native American racialethnic backgrounds - face exclusion due to a number of structural and psychological barriers levied against them (Eaton, Saunders, Jacobson, \& West, 2020; King, 2016; Musu-Gillette, de Brey, McFarland, Hussar, Sonnenberg, \& Wilkinson-Flicker, 2017; Wang \& Degol, 2016). 
Notably, STEM training programs are reliant upon group-based work to meet the demands of an increasingly collaborative workforce (and the resultant accreditation criteria, e.g., ABET, 2020;

Felder, Brent, \& Prince, 2013). STEM programs thus uniquely threaten belonging and simultaneously advantage those who are able to develop it.

\section{Growth Mindset and Belonging: From Buffering to Filtering Contextual Cues}

There is a large literature on the correlates of belonging (Allen, Kern, Vella-Brodrick, Hattie, \& Waters, 2018), though few studies demonstrate factors that directly influence it (for a notable exception, see the "social belonging intervention," which supports belonging by reframing how students interpret adversity; for a review, see Walton \& Brady, 2020). Emerging evidence, however, suggests that objective signals from the environment (Cheryan et al., 2013; Cheryan, Meltzoff, \& Kim, 2011; Cheryan, Plaut, Davies, \& Steele, 2009; Murphy, Steele, \& Gross, 2007) and growth mindset beliefs (Dweck \& Leggett, 1988; Good et al., 2012; Hong, Dweck, Chiu, Lin, \& Wan, 1999) are causally linked to belonging. Both lines of research draw on the theory of social identity threat (Steele, Spencer, \& Aronson, 2002). This theory describes how group-based threats (e.g., stereotypes) may be made salient to members of those groups (e.g., via cues of underrepresentation), and how such threats can produce within group members disruptive internal experiences, such as physiological stress responses, performance anxiety, and belonging uncertainty (Johns, Inzlicht, \& Schmader, 2008; Schmader, Johns, \& Forbes, 2008; Walton \& Cohen, 2007).

More specifically, a long history of stereotype threat literature suggests that negative stereotypes about women's math ability can undermine their performance in quantitative fields (e.g., Davies, Spencer, Quinn, \& Gerhardstein, 2002; Spencer, Steele, \& Quinn, 1999; for a meta-analysis, see Nguyen \& Ryan, 2008). These negative effects are theorized to arise broadly 
due to women's apprehension about confirming the stereotypes (Ben-Zeev, Fein, \& Inzlicht, 2005; Cadinu, Maas, Rosabianca, \& Kiesner, 2005). This apprehension, coupled with actual performance decrements, may jeopardize women's own ability beliefs as well as their perceptions of others' beliefs about their abilities. Both of these factors may erode a sense of belonging in a higher education context in which ability is critical to feeling (and being) accepted and valued (Lewis \& Hodges, 2015). Here, beliefs about the nature of ability play an important role. Under a fixed mindset, these ability concerns may not be able to be assuaged, because ability is seen as immovable. Under a growth mindset, however, these ability concerns can be overcome, because ability is seen to be malleable. Thus, whether or not one's actual ability is suboptimal, concerns about the level of one's ability may be mitigated by believing in the potential for that ability to improve.

For example, if a female student in a calculus class perceives a high level of agreement in that class with gender stereotypes about math ability (e.g., women are not as good as men in math; see Good et al., 2012), she may begin to question both her own math ability (due to performance anxiety and actual instances of underperformance) as well as how her classmates view that ability. Holding a growth mindset in this situation may buffer against any deleterious conclusions that she might draw about her own sense of belonging in math as a result of her threatened ability beliefs. Regardless of how low she may believe her ability to be, this belief does not carry inevitable consequences for her belonging, because she sees her ability as improvable.

Although buffering processes almost certainly account for part of the relationship between mindset beliefs and belonging, the existing literature has yet to fully consider the filtering role that individual mindsets may play in students' perceptions of their context. In 
addition to forestalling the negative internal processes (e.g., ability uncertainty) that social identity threat instigates, personally holding a growth mindset may support belonging by shaping how individuals interpret their context. Put in statistical terms, we hypothesize that personal growth mindset beliefs operate both as a moderator of the relationship between threat and belonging as well as an exogenous variable that begins a cascade of relationships in which perceptions of the context influence belonging. Thus, holding a growth mindset may support students' sense of belonging not only because it eases the ability anxiety that can result from environmental stressors, but also because it changes how they construe the very sources of those stressors in the first place.

More specifically, we theorize that students' perceptions of their peers' and instructors' growth mindset beliefs are both belonging-relevant and likely to be informed by students' personal mindset beliefs. They are belonging-relevant because they serve as signals of an institution's value system (Murphy \& Dweck, 2010), communicating to students how trustworthy the institution is and to what extent they belong (or can come to belong). Though somewhat scarce, there is growing empirical evidence that students' perceptions of their instructors' growth mindset beliefs influence their belonging.

For example, across four studies and 1,669 participants, Muenks and colleagues (2020) found that undergraduate students' perceptions of their instructors' mindsets predicted their psychological experiences_-including belonging — in their STEM classes. Two of these studies manipulated and assessed the effects of perceived instructor mindsets on belonging experimentally, and two utilized experience sampling methodology to capture in-the-moment associations between perceived instructor mindset and belonging. Similarly, Rattan and 
colleagues (2018) found that underrepresented students' perceptions of their instructors' mindsets predicted their belonging in STEM.

In contrast to the growing investigation of students' perceptions of their instructors' mindsets, there is a lack of research on students' perceptions specifically of their peers' mindsets. However, Good and colleagues (2012) found that students' reports of the mindset beliefs of "people" in their calculus class predicted belonging in that class. Given these preliminary results, and in light of the findings on perceived instructor mindset beliefs, we hypothesize that students' perceptions of their peers' growth mindset beliefs will independently influence their belonging. That is, students' perceptions of their peers' mindsets may be another signal of an institution's mindset, and thus another indicator of their school's trustworthiness and ability to support belongingness.

Students' perceptions of others' growth mindset beliefs are likely to be informed by students' own mindsets due to egocentric biases involved in the discernment of others' thoughts, beliefs, and mindsets (Critcher \& Dunning, 2009; Epley, Keysar, Van Boven, \& Gilovich, 2004; Kenny \& DePaulo, 1993). That is, individuals tend to rely on their own self-views when inferring the views of others, because their own beliefs are more accessible than alternative relevant information (Chambers, Epley, Savitsky, \& Windschitl, 2008; Epley \& Eyal, 2019; Epley \& Waytz, 2010). Additionally, students who endorse a growth mindset may exhibit confirmation bias in that they are more primed to recognize and remember growth mindset signals (and overlook fixed mindset signals) due to the cognitive salience of growth mindset for them (Nickerson, 1998). In the same way, those with more of a fixed mindset may be more likely to notice fixed mindset signals, especially because people in general tend to be more attuned to negative feedback (Baumeister, Bratslavsky, Finkenauer, \& Vohs, 2001). Indeed, Muenks et al. 
(2020, Studies 3 and 4) found that STEM students' personal mindset beliefs predicted their perceptions of their instructors' mindset beliefs (Study $3 r=.43$; Study $4 r=.35$ ), and Good et al. (2012) found that math students' personal mindset beliefs predicted their perceptions of environmental mindsets $(r=.50)$.

\section{The Role of School Trust}

Although the literature offers preliminary evidence for the importance of mindset beliefs to belonging, the mechanisms of these relationships are as yet unidentified. One possible mechanism is school trust: the belief that agents of a school will treat all students fairly (Cohen, Steele, \& Ross, 1999; Yeager, Purdie-Vaughns, Garcia, Apfel, Brzustoski, Master, et al., 2014). Though (to our knowledge) there are no studies assessing the relationships among mindsets, trust, and belonging in higher education, there is both theoretical and empirical support for the hypothesis that mindset beliefs inform institutional trust from the fields of consumer and organizational psychology.

At the individual level, those who endorse a growth mindset may be more likely to trust their institution because of their belief in people's (and organizations') ability to change. In the event of a violation of trust, for example, growth mindset individuals will be more likely to give others the benefit of the doubt and will be less likely to draw permanent conclusions about the general untrustworthiness of the trust violator (Murphy \& Dweck, 2016). Indeed, Haselhuhn and colleagues (2010) found that those who endorsed a growth mindset were more likely than those who endorsed a fixed mindset to rebuild trust in a partner who originally violated that trust. 
Applied to education, students with a growth mindset are expected to maintain trust in their institution even in the face of occasional incidents of unfair treatment.

Though mindsets have traditionally been examined at the individual level, they can also be adopted and communicated at the group level. For example, organizations communicate to individuals the extent to which they view intelligence as fixed or malleable through such signals as reward structures and shared norms (Murphy \& Dweck, 2010). Perceptions of these grouplevel mindsets inform individual beliefs about the values the organization holds, especially with regard to the individuals who are members of that organization. Applying this perspective to higher education, if students believe that an organization values individual progress and the ability to develop over time (i.e., an institutional growth mindset), they will be more likely to believe that institutional agents (e.g., faculty) will treat them fairly. That is, they will have more trust in their school because they do not feel as though they will be viewed and evaluated through the lens of a fixed binary of being smart or not. Supporting this hypothesis, Canning et al. (2020) found that employee perceptions of their company's institutional mindset— the extent to which an organization believes ability is fixed or malleable-drove employees' trust in those companies (see Emerson \& Murphy, 2014, for a review of similar findings).

We hypothesize that trust will not only follow from personal and perceived instructor and peer mindset beliefs, but will also be related to a sense of belonging. When individuals enter a new context, they search for ways to determine whether or not they belong or can come to belong (Cohen \& Garcia, 2008; Walton \& Brady, 2017). One piece of information that could be used to make this determination is the extent to which the institution can be trusted, that is, the extent to which the institution will enact fair treatment (Cohen et al., 1999). If a student feels as though their school will treat them fairly, they will be more likely to feel as though they belong 
in that environment. Empirically, there are no direct assessments of the relationship between school trust and belonging in higher education contexts (to our knowledge). However, there is a fairly wide literature on the robust relationship between belonging and perceived school climate (Cabrera, Nora, Terenzini, Pascarella, \& Hagedorn, 1999; Chavous, 2005; Hurtado \& Carter, 1997; Mounts, 2004), which is conceptually similar to school trust. Definitions of school climate, though broader than school trust, commonly include perceptions of prejudice and discrimination enacted by representatives of the school (Hurtado, Clayton-Pedersen, Allen, \& Milem, 1998). This parallels the conceptual definition of school trust as a belief in the fairness of an institution's representatives (Cohen et al., 1999). Thus, although the role of school trust has not been directly examined as a correlate of belonging, there is both theoretical and empirical precedent to hypothesize such a relationship.

\section{The Proposed Model: Growth Mindset as a Filter of Contextual Cues}

We propose a theoretical process model in which personal growth mindset beliefs relate to belonging through perceived peer mindsets, perceived instructor mindsets, and school trust; see Figure 1 for a visual depiction of the model. More specifically, we hypothesize that students' individual growth mindset beliefs inform their perceptions of the mindset beliefs of their peers and instructors. These beliefs then contribute to students' feelings of trust in their school, which ultimately influence their sense of belonging within the institution. Although we expect the indirect pathways as specified to account for a meaningful amount of the relationship between personal growth mindset beliefs and belonging, we do still hypothesize the existence of direct relationships as outlined in the model. For example, growth mindset beliefs may relate to school trust directly, and not entirely through perceptions of others' mindset beliefs. As such, one of our 
substantive goals was to test and refine this base model against the data we collected in order to evaluate the direct and indirect nature of the proposed relationships.

\section{Moderating Factors}

The relationships specified in our theoretical model are expected to vary according to a number of contextual and individual factors. In this paper, we explore the moderating role of two possible factors: STEM education context and student gender identity.

\section{Moderation by STEM Education Context}

The two samples of STEM undergraduates in the present studies were drawn from very different higher education contexts. In Study 1, the participants were students in a specialized school of engineering at a research-intensive university. The school is selective, competitive, and fairly homogeneous in terms of income (primarily high-income; 11\% Pell grant eligible during the study year). Racially, the school is fairly representative of college student demographics in the United States overall (majority White: $52 \%$ in the study compared to 55\% nationally; U.S. Census Bureau, 2018). The population from which this sample was drawn reflects that of the existing literature in this field. In Study 2, the participants were students taking introductory mathematics courses at a community college. The school is open-access and heterogeneous both in terms of race (57\% African American, Hispanic, Native American, and/or Hawaiian/Pacific Islander during the study years) and income level (37\% Pell grant eligible during the study years).

These contextual differences in institution type, selectivity, STEM field, and demographic composition are likely to alter the relationships specified in our model. For example, research-intensive universities that are academically selective, competitive, and which require on-campus housing present a different psychological experience than community 
colleges do. The role of perceived peer mindset may be minimized in community college settings in which many students commute to school, rather than live on or near campus (as is often the case with research universities), because interactions with fellow students are less likely to occur. Similarly, the relationship between school trust and belonging may be attenuated in community college, because the school itself may be less central to the daily experiences of community college students compared to those who live on or near the campus of universities. Indeed, researchers have found that student experiences of belonging vary meaningfully across contextual characteristics such as institution type (Gopalan \& Brady, 2020; Strayhorn, 2012) and degree program (Strayhorn, 2019).

\section{Moderation by Student Gender Identity}

STEM fields (especially engineering, computer science, and physics) present belonging challenges specifically to women for a number of reasons, including negative stereotypes, discrimination, and cultures of masculinity, all of which translate into underrepresentation at all levels of the STEM pipeline (Cheryan, Ziegler, Montoya, \& Jiang, 2017; Eagan, Stolzenberg, Ramirez, Aragon, Suchard, \& Rios-Aguilar, 2016; U.S. Bureau of Labor Statistics, 2019; U.S. Department of Education, National Center for Education Statistics, 2019).

Considering these group-specific threats to belonging, the relationships between mindset beliefs and belonging may vary according to group membership. That is, women's belonging may be more strongly related to their individual mindsets and their perceptions of the context than men's belonging. Indeed, prior research has found that growth mindset beliefs (individual or environmental) promote belonging for women but not men (Good et al., 2012), and objective cues that activate gender-based threats undermine belonging for women but not men (Cheryan et al., 2009). In line with these findings, we hypothesize that the relationships outlined in our 
theoretical model will vary according to gender identity, though we do not make specific predictions about the directionality of these differential relationships. For example, relative to men, women's personal growth mindsets may be less strongly linked to their perceptions of their instructors' and peers' mindsets, because they are aware of the heightened possibility of gender stereotyping in the STEM context. Thus, they may assume that others hold more threatening (i.e., more fixed) beliefs about the nature of ability. Conversely, women's personal growth mindsets may be more strongly linked to the perceived mindsets of others, because relying upon their own personal beliefs to infer the beliefs of others may be safer than seeking out the (possibly) more threatening actual beliefs of others.

We recognize that many of the threats to belonging in STEM faced by women are also faced by members of other traditionally underserved groups, including underrepresented racialethnic minority students, first-generation students, and low-income students. In the present studies, we focused on gender identity in order to draw a direct comparison to the few existing studies on the relationship between growth mindset beliefs and belonging in higher education STEM settings, which focused on differences across gender groups. We were also limited in our ability to conduct additional subgroup analyses due to sample size. An important next step for this line of research is to test and compare the model across different groups of students, especially those that face systemic disadvantage, such as students from minoritized racial-ethnic backgrounds.

\section{Current Studies}

Across two studies in postsecondary STEM contexts, we investigate the relationships among growth mindset beliefs and perceptions of the school context (others' mindset beliefs and school trust) to better understand how belonging in STEM fields develops and may be supported. 
We also explore moderation by STEM education context and gender to see how these relationships may unfold differently based on contextual and individual factors.

\section{Common Analytic Approach for Both Studies}

First, we ran a series of stepwise OLS regression models predicting belonging to examine the relative effects of students' growth mindset beliefs, perceptions of their instructors' and peers' mindset beliefs, and school trust. To explore differential effects due to gender identity, we tested the interaction term of each growth mindset variable with a dummy-coded gender variable. When comparing within-model independent variables, we used standardized coefficients. When comparing independent variables across gender groups, we used unstandardized coefficients.

Second, we used exploratory and confirmatory factor analyses to examine the latent makeup (i.e., the "measurement model") of the data. Using the OpenMx package in R (version 2.15.5; Neale, Hunter, Pritikin, Zahery, Brick, Kirkpatrick, et al., 2016), we then fit a series of structural equation models (SEM) using maximum likelihood to estimate and refine our base theoretical predictions of the relationships among the latent constructs (i.e., the "structural model"; see Figure 1). To control for first generation status, low-income status, underrepresented racial-ethnic minority status, and gender, we specified paths between these covariates and all variables contained in the model. Full information maximum likelihood was used to estimate missing data, avoiding the biases introduced by case deletion (Schafer \& Graham, 2002).

We determined SEM to be the appropriate analysis for two primary reasons. First, it allows for the specification and testing of expected relationships among variables in a theoretical model (Maruyama, 1998). In this way, it examines the plausibility of the model and provides additional information that can lead to theory refinement. Second, modeling observed variables 
as latent entities comprised of shared variance reduces measurement error and can increase statistical precision (Cole \& Preacher, 2014).

To refine the overall model, we compared the estimated base theoretical model to nested models that removed nonsignificant regression paths. To explore moderation by gender, we fit and compared three multi-group models that tested for equality of regression paths, latent means, and variances across men and women.

To improve interpretability of parameter estimates and account for differences in measures used in Studies 1 and 2, we modeled the latent variables off of standardized indicator variables. In this way, partial regression coefficients in the model are roughly interpretable as changes in standard deviation units in the endogenous variables for every one standard deviation increase in the associated exogenous variable. As such, the estimates are somewhat comparable across studies. For such comparisons to be tenable, the variances of the indicator variables between and within studies must be assumed to be the same. As described in the supplemental text of Online Resource 1, we found descriptive and inferential evidence to support this assumption (e.g., see Table 1 for a comparison of the variances of the variables transformed to be on the same scale across studies). For additional information on the general analytic approach of the study, see Online Resource 1.

\section{Study 1}

\section{Method}

\section{Procedure and Participants}

The data used for this study were drawn from a wider project investigating the psychosocial underpinnings of inequity in higher education. We sent an online survey to all undergraduate engineering students at a selective public university in the mid-Atlantic midway 
through the fall semester. Of these, 957 (34\%) responded. The study sample included $48 \%$ women, 13\% underrepresented racial-ethnic minority (URM; African American, Hispanic, Native American, and/or Hawaiian/Pacific Islander), 53\% White, and 24\% Asian students. The sample closely resembled the engineering school in terms of race and first-generation and income status, though there was a higher proportion of women in the sample than in the population (48\% versus $33 \%)$.

\section{Measures}

Adapting prior measures of growth mindset (Dweck, 1999; Dweck, Chiu, \& Hong, 1995), we measured growth mindset in the engineering context, including personal (three items, e.g., "Most people can learn to be good at engineering"; 1 = strongly disagree, $6=$ strongly agree; $\alpha=0.59$ ); perceived peer (three items, e.g., "Most of my classmates think that your engineering ability is something about you that you can't change very much [reverse-scored]"; 1 = strongly disagree, $6=$ strongly agree $; \alpha=0.88$ ), and perceived instructor mindset beliefs (four items, e.g., "My instructors believe that everybody can be good at engineering."; 1 = strongly disagree, $6=$ strongly agree $; \alpha=0.69)$.

We measured school trust with an existing scale adapted for the postsecondary context (three items, e.g., "I am treated fairly by faculty and staff at [school name]."; $1=$ strongly disagree, $7=$ strongly agree $; \alpha=0.81 ;$ Yeager, Purdie-Vaughns, Hooper, \& Cohen, 2017).

We measured belonging with the Sense of Social and Academic Fit in Engineering scale (ten items, e.g., "I belong in Engineering at [school name]."; $1=$ strongly disagree, $7=$ strongly agree; $\alpha=0.88$; Walton, Logel, Peach, Spencer, \& Zanna, 2015).

Institutional data, including student demographics were merged onto the survey data and deidentified prior to our receipt of them. We used the following demographics as control 
variables in our models: underrepresented racial-ethnic minority (URM) status $(0=$ non-URM [White, Asian, or Unknown/Other], 1 = URM [Black, Hispanic, and/or Native American]), gender $(0=$ male, 1 = female), first generation status (students for whom neither parent held a four-year college degree; $0=$ continuing generation, 1 = first generation $)$, low-income status $(0=$ not Pell grant eligible, 1 = Pell grant eligible), and prior achievement (high school math standardized ACT/SAT test score).

\section{Results}

In this study, we tested two broad predictions. First, we developed a directional model (Figure 1) in which we hypothesized that personal growth mindset would predict perceived peer mindset and perceived instructor mindset, which would together predict school trust. Trust, then, would ultimately predict belonging. Second, we hypothesized that these relationships would vary by gender.

\section{OLS Regression Models}

For a descriptive summary of the study variables, see Table 1. In the sequential OLS models, our first prediction concerning the directional model was partially supported. We found in the first step (Table 2, Model 1) that the more participants endorsed a personal growth mindset, the higher they reported their sense of belonging to be, $b^{*}=0.17, S E=0.03, p<.001$, 95\% CI [0.11, 0.24]. To explore the hypothesized mediational pathways, we entered perceived peer and perceived instructor mindsets at step 2 (Model 2) and school trust at step 3 (Model 3). These hypothesized relationships were partially supported, such that the size of the effect of personal growth mindset decreased at each step, and each additional variable accounted for a significant portion of the variance of belonging in the final model. In other words, the total effect of personal mindset on belonging was partially explained by the peer mindset, instructor 
mindset, and school trust variables; and the effect of the instructor mindset variable was then partially explained by the school trust variable (for an OLS model in which the mindset variables predict trust, see Table S3 in Online Resource 2). Unexpectedly, perceived peer mindset did not have a relationship with belonging in Model $2\left(b^{*}=0.04, S E=0.04, p=.253,95 \%\right.$ CI [-0.03, 0.12]), and the inclusion of school trust actually increased the size of the coefficient of peer mindset: $b^{*}=0.08, S E=0.04, p=.021,95 \% \mathrm{CI}[0.01,0.15]$. This suggests that although trust may explain the relationship between perceived instructor mindset and belonging, the same may not hold for the relationship between perceived peer mindset and belonging.

Our second prediction about the moderation of the hypothesized relationships by gender was also partially supported (see Table 3). Gender did not moderate the relationship between personal growth mindset and belonging (Growth Mindset $\mathrm{x}$ Female $b^{*}=0.07, S E=0.06, p=$ $.244,95 \%$ CI $[-0.05,0.19])$, though descriptively women experienced a stronger positive relationship between growth mindset and belonging $(b=0.24, S E=0.05, p<.001,95 \% \mathrm{CI}$ $[0.14,0.34])$ than men $\operatorname{did}(b=0.14, S E=0.05, p=.006,95 \%$ CI $[0.04,0.24])$. Gender did moderate the relationship between perceived peer growth mindset and belonging (Perceived Peer Growth Mindset x Female $b^{*}=0.13, S E=0.06, p=.033,95 \%$ CI $[0.01,0.24]$; see Table 3 and Figure 2), such that women's perceptions of their peers' growth mindset beliefs were positively related to their sense of belonging $(b=0.14, S E=0.05, p=.005,95 \% \mathrm{CI}[0.04,0.24])$, whereas no such relationship existed for men $(b=0.01, S E=0.05, p=.830,95 \%$ CI $[-0.08,-0.10])$. Unexpectedly, no moderating effect of gender was found between perceived instructor growth mindset and belonging.

In addition to our two main predictions, we found that the strongest predictors of belonging were school trust and gender. Entering trust into the main effects model $\left(b^{*}=0.36, S E\right.$ 
$=0.03, p<.001,95 \%$ CI $[0.30,0.42])$ doubled the overall amount of explained variance (Model 3 adj. $R^{2}=.22, \Delta$ adj. $\left.R^{2}=.11\right)$. Trust was a substantially stronger predictor of belonging than all growth mindset variables, more than four times as large as perceived instructor growth mindset, the second-largest non-covariate coefficient.

Across models, gender maintained a significant and stable negative relationship with belonging (average $b^{*}=-0.15$; Model $3 b^{*}=-0.15, S E=0.06, p=.015,95 \%$ CI [-0.27, -0.03$]$ ), such that female students reported lower levels of belonging $(M=4.96, S D=0.98)$ than male students $(M=5.13, S D=0.98)$. Notably, being female (relative to male and conditioned on the covariates) was associated with more of a difference (in standard deviation units) in belonging than being of URM or first-generation status.

\section{Latent Variable Measurement Model}

Prior to fitting confirmatory measurement or structural models, we investigated the latent composition of the data with exploratory factor analyses. A correlation table of the constituent standardized variables is presented in Online Resource 2 (Table S2). Using the hypothesized five-factor model and promax rotation, we identified five items that violated simple structure with poor loadings on their respective factors and/or unexpected cross loadings with other factors. We dropped these items and re-estimated the model (for the dropped items, see Online Resource 1). The resulting five-factor model followed simple structure and, given existing theory, outperformed alternative factor specifications. We used the subset items to estimate a

five-factor confirmatory measurement model with simple structure constraints (see Figure 2; for standardized parameter estimates, see Table S4 in Online Resource 2): Comparative fit index $(\mathrm{CFI})=0.93$, Tucker-Lewis Index $(\mathrm{TLI})=0.92$, root mean square error of approximation $($ RMSEA $)=0.065,95 \%$ CI $[0.059,0.071]$. Though these fit statistics are slightly outside the 
traditional range of values indicating good fit (Hu \& Bentler, 1999; Schreiber, Nora, Stage, Barlow, \& King, 2006), they are satisfactory for the purposes of representing a latent construct in a structural model.

\section{Latent Variable Structural Model}

After fitting the full theoretical model (see Figure 1), model comparison likelihood ratio tests revealed that the hypothesized paths from personal growth mindset to trust and belonging, as well as perceived peer growth mindset to belonging, were not significant (and did not affect model fit upon their removal, $\left.\chi^{2}(3)=2.38, p=.498\right)$. However, the final trimmed model $\left(R^{2}=\right.$ .22) presented a satisfactory fit to the data: $\mathrm{RMSEA}=0.058,95 \% \mathrm{CI}[0.053,0.063], \mathrm{CFI}=0.93$, TLI $=0.90 ;$ see Figure 4.

The entirety of the relationship between personal growth mindset and belonging was explained by the indirect effects of personal growth mindset on belonging through perceived peer mindset, perceived instructor mindset, and school trust, overall indirect $b^{*}=0.15$, likelihood-based $95 \%$ CI $[0.10,0.21]$. In other words, the direct effect of personal growth mindset on belonging was reduced to non-significance after taking into account the hypothesized relationships between perceived mindsets, trust, and belonging.

As predicted, we found evidence of moderation by gender. Multigroup model analyses revealed significantly worsened fit among all models that imposed equality constraints—on all parameters $(-2 \mathrm{LL}=43736.47, \mathrm{AIC}=3088.47)$, all regression coefficients $(-2 \mathrm{LL}=43618.52$, $\mathrm{AIC}=3056.52)$, all latent variable means $(-2 \mathrm{LL}=43635.14, \mathrm{AIC}=3077.14)$, and all latent variable variances and covariances $(-2 \mathrm{LL}=43616.04, \mathrm{AIC}=3080.04)$-across gender groups (all $p$ 's of likelihood ratio tests $<.004$ ), relative to the models allowing all parameters to vary freely between groups $(-2 \mathrm{LL}=43568.13, \mathrm{AIC}=3064.13)$. In other words, allowing the 
estimated parameters to vary freely across gender presented a better fit than assuming that the main parameters (regression paths, means, and variances) were the same for both genders.

When estimating parameters separately by gender (see Figures 5 and 6), women exhibited stronger relationships between personal growth mindset beliefs and perceived growth mindset beliefs of peers $\left(b^{*}=0.68, S E=0.08, p<.001,95 \%\right.$ CI $\left.[0.52,0.86]\right)$ and instructors $\left(b^{*}\right.$ $=0.52, S E=0.08, p<.001,95 \%$ CI $[0.38,0.68])$ than men $\operatorname{did}\left(b^{*}=0.37, S E=0.08, p<.001\right.$, $95 \%$ CI $[0.24,0.54] ; b^{*}=0.30, S E=0.06, p<.001,95 \%$ CI $[0.19,0.44]$, respectively). In line with our predictions, the stronger relationship between personal mindsets and perceived instructor mindset beliefs translated into a stronger indirect effect of personal mindset through perceived instructor mindset on trust for women $\left(b^{*}=0.35,95 \% \mathrm{CI}[0.12,0.46]\right)$ relative to men $\left(b^{*}=0.25,95 \%\right.$ CI $\left.[0.21,0.54]\right)$. Moreover, women $\left(b^{*}=0.10,95 \%\right.$ CI $\left.[0.05,0.17]\right)$ and men $\left(b^{*}=0.10,95 \%\right.$ CI $\left.[0.05,0.19]\right)$ displayed similar indirect effects of personal growth mindset on belonging through perceived instructor mindset and trust, even though the residual regression coefficient of trust and belonging was stronger for men $\left(b^{*}=0.40,95 \% \mathrm{CI}[0.30,0.51]\right)$ than it was for women $\left(b^{*}=0.27,95 \% \mathrm{CI}[0.17,0.38]\right)$. Because the regression path between trust and belonging represents the residual relationship after taking into account the effect of the prior variables, more of the relationship between personal growth mindset and belonging is explained through perceptions of instructor mindset and its effect on trust for women than it is for men.

In addition to our two main predictions, we found that perceived instructor growth mindset and trust accounted for the vast majority of the total indirect effect of personal growth mindset on belonging. Specifically, of the total variance in belonging explained by personal growth mindset, 95\% was attributable to pathways through perceived instructor growth mindset 
and trust (indirect $b^{*}=0.20,95 \%$ CI $[0.14,0.27]$ ), whereas $5 \%$ was attributable to pathways through perceived peer growth mindset (indirect $b^{*}=-0.05,95 \%$ CI $[-0.08,-0.02]$ ).

\section{Study 1 Discussion}

These results provide general support for a theoretical model decomposing the relationship between personal growth mindset beliefs and belonging into relationships among the perceived contextual factors of others' mindset beliefs and the school's trustworthiness. They also provide evidence of the hypothesized moderation of these relationships by gender.

Though all primary study variables predicted belonging in the final OLS regression model, school trust accounted for the majority of explained variance. When modeled using structural equation techniques, perceptions of the context - perceived instructor growth mindset, perceived peer growth mindset and school trust - fully explained the relationship between personal growth mindset and belonging.

As expected, many of the theorized relationships varied between women and men, who reported different levels of overall belonging. Relative to men, women's personal growth mindset beliefs were more strongly related to their perceptions of others' mindset beliefs, and more of the relationship between their personal growth mindset beliefs and belonging was explained via perceptions of instructor mindset and trust. For additional discussion of the Study 1 results, see Online Resource 1.

\section{Study 2}

\section{Method}

\section{Procedure and Participants}

The data used for this study were drawn from a larger study in which two motivation interventions were tested in a randomized controlled trial in introductory math courses within a 
community college system in the Southeast. The present analysis only included the students who were randomly assigned to be in the control condition of the intervention $(N=2,083)$. These students completed self-report questionnaires for course credit at four separate time points throughout the semester: weeks 1, 3, 5, and 12 out of a total of 15 weeks. For additional information on the Study 2 method, see Online Resource 1.

The study sample included $60 \%$ female, $58 \%$ URM, $28 \%$ White, and $15 \%$ other or unknown race students, closely reflecting the college system's overall demographic breakdown at that time. However, it is worth noting that study participants were more likely to be full time (53\%) and less likely to be low-income (Pell grant eligible; $11 \%)$ than students throughout the system (34\% full time and 37\% low-income on average throughout the course of the study).

\section{Measures}

The measures analyzed for this study were not exact duplicates of those used in Study 1, but they measure the same constructs (see Table A1 in the Appendix for a direct comparison of each measure used across studies). As such, they were expected to exhibit similar patterns despite minor differences in item wording and response options.

As in Study 1, we measured personal growth mindset (three items, e.g., "My math ability is something about me that I can't change very much [reverse-scored]"; 1 = strongly disagree, 6 = strongly agree $; \alpha=0.86 ;$ Blackwell, Trzesniewski, \& Dweck , 2007; Yeager, Bryk, Hausman, Muhich, \& Morales, 2013), perceived peer growth mindset (items identical to Study 1; $1=$ strongly disagree, $5=$ strongly agree; $\alpha=0.87)$, and perceived instructor growth mindset (three items, e.g., "My math teacher seems to believe that only a few students will understand the hardest problems [reverse-scored]"; $1=$ not at all, $5=$ extremely true $; \alpha=0.62$; adapted from Dweck, 1999 and Dweck et al., 1995). 
We also measured school trust (three items, e.g., "To what degree are you treated with respect by teachers and other faculty/staff at [school]?"; 1 = not at all, 5 = an extreme amount; adapted from Roeser, Midgley, \& Urdan, 1996 and Voelk1, 1996; $\alpha=0.79$ ) and belonging (three items, e.g., "How much do you feel like you matter in this class?"; $1=$ not at all, $5=$ an extreme amount; $\alpha=0.80$; Roeser et al., 1996).

In line with the temporal hypotheses advanced by our theoretical model, we used personal growth mindset measured at time 1 (week 1 of the class), perceived peer and instructor growth mindset at time 2 (week 3), and school trust and belonging at time 4 (week 12; school trust was not measured at time 3, week 5).

In this study, we used the same set of covariates and coding as those described in Study 1, with two variations. First, students self-reported their demographics. Second, to measure prior achievement, we created a standardized variable using a combination of four prior achievement variables (self-reported high school GPA, college-entry standardized test math score, selfreported grade in their most recent math class, and college GPA) that most strongly predicted grades in the course taken during the study (for a similar procedure, see Canning, Harackiewicz, Priniski, Hecht, Tibbetts, \& Hyde, 2018).

\section{Results}

\section{OLS Regression Models}

For a descriptive summary of the study variables, see Table 1. In the sequential OLS models, we found partial support for our theoretical model. As expected, and as seen in Study 1, personal growth mindset predicted belonging, $b^{*}=0.20, S E=0.04, p<.001,95 \%$ CI $[0.12$, 0.28] in the first step (see Table 4, Model 1). Again, entering perceived peer mindset and perceived instructor mindset (Model 2) and school trust (Model 3) reduced the effect of personal 
growth mindset on belonging at each step. However, the vast majority of this reduction was due to school trust $\left(b^{*}=0.55, S E=0.03, p<.001,95 \%\right.$ CI $\left.[0.49,0.62]\right)$, which improved the model's overall explanatory power: adj. $R^{2}=.34, \Delta$ adj. $R^{2}=.31$. Perceived peer and instructor growth mindset, on the other hand, explained a negligible amount of variance in belonging when added to the base model (Model 1): adj. $R^{2}=.04, \Delta$ adj. $R^{2}=-.001$. The minute (and negative) change in adjusted $R^{2}$ indicates that the addition of the peer and instructor mindset variables does not improve the predictive strength of the model beyond what would be expected by the inclusion of any two variables regardless of association with the outcome measure. In other words, the penalty of adding two independent variables when adjusting the raw $R^{2}$ value was greater than the improvement in prediction afforded by the two variables. Interestingly, in the final model (Model 3), the only significant predictors of belonging (including demographics and prior achievement) were personal growth mindset, instructor growth mindset (negatively), and school trust.

These results suggest that the total effect of personal mindset on belonging was not explained by the perceived mindset variables to the extent that we predicted. However, they also indicate that school trust does account for a substantial amount of the relationship, as we hypothesized.

Our second prediction about the moderation of the hypothesized relationships by gender was again partially supported, though to a lesser extent than seen in Study 1. Gender did not moderate the relationship between personal growth mindset and belonging, $b^{*}=0.10, S E=0.07$, $p=.196,95 \%$ CI $[-0.05,0.24]$. Gender did moderate the relationship between perceived instructor growth mindset and belonging (Perceived Instructor Growth Mindset x Female $b^{*}=$ 0.22, $S E=0.07, p=.003,95 \%$ CI [0.08, 0.36]; see Table 3 and Figure 7), such that women's 
perceptions of their instructors' growth mindset beliefs were not related to their sense of belonging $(b=-0.01, S E=0.06, p=.876,95 \%$ CI $[-0.12,0.10])$, whereas men's perceptions were negatively related to their sense of belonging $(b=-0.24, S E=0.06, p<.001,95 \%$ CI [$0.37,-0.11])$. Unexpectedly, and in contrast to Study 1 , no moderating effect of gender was found between perceived peer growth mindset and belonging.

In addition to the study's two main predictions, we found that the strongest (and only) predictors of belonging were personal growth mindset and school trust. Across models, gender did not predict belonging, average $b^{*}=-0.06$, final $b^{*}=-0.06, S E=0.07, p=.413,95 \%$ CI [$0.20,0.08]$, reflecting the similarity in belonging reported by men $(M=3.54, S D=0.92)$ and women $(M=3.61, S D=0.86)$.

\section{Latent Variable Measurement Model}

As in Study 1, we first used exploratory factor analysis to probe the latent composition of the data. A correlation table of the constituent standardized indicator variables is presented in Online Resource 2 (Table S6). The hypothesized five-factor model with promax rotation provided evidence of simple structure and outperformed alternative specifications. The confirmatory model with simple structure constraints (see Figure 8 and Table S7 in Online Resource 2) fit the data well: $\mathrm{CFI}=0.98, \mathrm{TLI}=0.97, \mathrm{RMSEA}=0.033,95 \% \mathrm{CI}[0.028,0.039]$ (Hu \& Bentler, 1999; Schreiber et al., 2006).

\section{Latent Variable Structural Model}

As in Study 1, to test our two main predictions - the fit of the hypothesized model and the moderation of the specified relationships by gender-we estimated a series of structural equation models. After fitting the full theoretical model (see Figure 1), model comparison likelihood ratio tests revealed that the direct paths from perceived peer growth mindset to trust 
and belonging were not significant (and did not affect model fit upon their removal, $\chi^{2}(2)=0.96$, $p=.618)$. The final trimmed model $\left(R^{2}=.55\right)$ presented a good fit to the data: $\mathrm{RMSEA}=0.023$, 95\% CI [0.018, 0.027], CFI = 0.98, TLI = 0.98; see Figure 9.

In line with our hypotheses, though in contrast to Study 1, personal growth mindset beliefs had direct (total direct $b^{*}=0.13,95 \%$ CI $\left.[0.07,0.20]\right)$ and indirect (total indirect $b^{*}=$ $0.10,95 \%$ CI $[0.05,0.15])$ effects on belonging. Unexpectedly, the relationships between perceived peer mindsets and school trust $\left(b^{*}=-0.03, S E=0.04, p=.438,95 \%\right.$ CI $\left.[-0.10,0.04]\right)$ and belonging were not significant $\left(b^{*}=0.02, S E=0.03, p=.472,95 \%\right.$ CI $\left.[-0.04,0.06]\right)$.

Contrary to our predictions, we did not find evidence of moderation by gender. Gender did not predict belonging in either the full $\left(b^{*}=-0.02, S E=0.05, p=.676,95 \%\right.$ CI $\left.[-0.12,0.08]\right)$ or the trimmed $\left(b^{*}=-0.02, S E=0.05, p=.651,95 \%\right.$ CI $\left.[-0.12,0.07]\right)$ models. Accordingly, multigroup analyses revealed that fixing the regression parameters $(-2 \mathrm{LL}=59360.68, \mathrm{AIC}=$ 5047.75) across male and female subgroups had no measurable impact on fit when compared to the fully-free joint model $(-2 \mathrm{LL}=59339.75, \mathrm{AIC}=5047.748), \chi^{2}(29)=20.93, p=.862$. However, fixing the latent means $(-2 \mathrm{LL}=59430.22, \mathrm{AIC}=5090.21)$ or the latent variances and covariances $(-2 \mathrm{LL}=59410.84, \mathrm{AIC}=5086.84)$ did significantly worsen fit (both $p$ 's $<.001)$. These results suggest that women and men had differing mean levels and variances on each latent construct, but the relationships between these constructs did not differ.

In addition to the two main predictions, we found that, of the total variance in belonging explained by personal growth mindset, $12 \%$ was attributable to pathways through perceived instructor growth mindset. This stands in contrast to Study 1, in which $95 \%$ of the explained variance in belonging was due to pathways through perceived instructor growth mindset. The indirect effect coefficient describing such pathways was not statistically different from zero 
(indirect $\left.b^{*}=0.02,95 \% \mathrm{CI}[-0.005,0.04]\right)$. The direct effect of personal growth mindset on belonging accounted for $65 \%$ of the explained variance, and the indirect effect of personal growth mindset through trust explained the remaining $23 \%$.

\section{Study 2 Discussion}

This study aimed to replicate the model and hypotheses developed and tested in Study 1 by using longitudinal data from a new sample of STEM undergraduates. Broadly, we found evidence that personal growth mindset relates to belonging both directly and indirectly through pathways associated with perceptions of instructors' mindsets and evaluations of the school's trustworthiness. Notably, the model estimated in this study (with longitudinal data, a different context, and more participants) fit the data better than the model estimated in Study 1, both in terms of the proportion of variance explained (Study $1 R^{2}=.22$; Study $2 R^{2}=.55$ ) and all model fit indices (e.g., Study 1 RMSEA = 0.065; Study 2 RMSEA = 0.023). Although the exact reasons for the improved model fit in this context remain to be explored in subsequent research, it may be the case that the specified relationships are more broadly applicable in the open-access college environment of Study 2 than in the competitive university context of Study 1. Student experiences of belonging in the community college setting may be somewhat more homogeneous than those in research universities, with fewer factors beyond those specified in the model (e.g., on-campus living) exerting their influence on students' sense of belonging. The lack of moderation by gender in this study provides partial support for this hypothesis, though more targeted investigation is warranted.

As in Study 1, school trust emerged as the strongest individual predictor of belonging and explained a substantial amount of the relationship between personal growth mindset and belonging. However, in this sample, personal growth mindset was the only mindset variable that 
significantly predicted belonging, even after taking into account both perceived peer and perceived instructor growth mindset beliefs. When modeled structurally, personal growth mindset had both direct and indirect effects on belonging. The direct effect of growth mindset on belonging accounted for the majority of the total effect, but indirect effects through perceptions of instructors' mindsets and school trust also explained a meaningful amount of the relationship.

Gender did not moderate any of the relationships. Relatedly, gender did not predict belonging in any of the models, reflecting similar mean levels of belonging reported by men and women in this sample. Additionally, the regression parameters describing the structural relationships among variables did not differ significantly for gender groups. For additional discussion of the Study 2 results, see Online Resource 1.

\section{General Discussion}

\section{Implications for the Theory Linking Mindsets and Belonging in Postsecondary STEM}

Our findings suggest that growth mindsets not only buffer against perceived environmental threats, but also provide a filter through which students construe future sources of such threats. In particular, personal mindset beliefs may shape individuals' interpretation of objective signals they receive about others' mindset beliefs, which may themselves constitute potential sources of threat (e.g., a professor's fixed mindset). These filtered perceptions may then inform the individuals' beliefs about their school's value system, particularly how it understands and treats ability. Beliefs about the nature of ability, when communicated at the institutional level, carry a number of implications. In these two studies, we examine one such implication: the perceived trustworthiness of the educational institution. School trust was a reliable and robust predictor of belonging, explaining a large amount of the relationships observed between personal and perceived growth mindset beliefs and belonging. These relationships are novel, and they 
provide a bridge to connect psychological perspectives on the utility of internal mindsets to sociological perspectives on the importance of external context.

This model contributes to existing social psychological theory describing how beliefs about intelligence relate to students' belonging in postsecondary STEM programs. To date, the relationship between growth mindset beliefs and belonging has been explained by a model of social identity threat, in which group-based threats are activated by the environment and buffered by growth mindset beliefs. Consequently, studies based on these theories posit (and find) differential effects of growth mindset beliefs across gender groups (e.g., Good et al., 2012). Our findings suggest an alternative and complementary function of mindset beliefs, in which individuals' perceptions of their social context (e.g., its trustworthiness) are filtered through their own mindsets. This filtering function of mindset beliefs may generalize beyond specific social groups under identity threat, with the caveat that the local context will continue to shape the relationships in meaningful and idiosyncratic ways.

\section{Implications for Efforts to Promote Belonging in Postsecondary STEM}

Practically, this model elucidates some of the psychological processes that may underly the development of belonging in higher education STEM fields, highlighting opportunities for targeted efforts to support students' belonging. Our results indicate that belonging is closely connected to experiences of school trust. Efforts to promote school trust should be made, including altering the climate of institutions of higher education to be more responsive to the needs of all students, especially those who face continued underrepresentation and stigmatization. The critical element of trust, as operationalized in the present studies, is perceived fair treatment by faculty and staff of the school. Thus, training institutional agents to better understand and support students from an array of backgrounds may promote perceptions of 
equitable treatment, which undergird feelings of school trust. In turn, heightened trust should promote belongingness.

Additionally, our model suggests that one approach to increasing belonging is changing the mindsets of students in STEM programs. By bolstering students' personal mindsets, their filter for perceiving the academic context may be shifted such that fewer signals are perceived to be threats. Considering the wide literature on the effectiveness of direct-to-individual growth mindset interventions (for a meta-analytic review, see Sarrasin, Nenciovici, Foisy, AllaireDuquette, Riopel, \& Masson, 2018), this approach presents an empirically-grounded next step in the institutional support of student belonging. However, focusing solely on the individual overlooks the critical role that institutional contexts themselves play in the academic and wellbeing outcomes of students. Overly emphasizing how students might change in order to experience better outcomes suggests that the deficits are in the students, not the system (Paunesku, 2019). As such, efforts should be made to change features of the institution, and the present model offers potential levers to do so.

In particular, cultivating a growth mindset culture among instructors may communicate to students key information about the institution in general. By developing and, critically, communicating instructors' growth mindset beliefs to students, an institution may be able to convey its own value system and foster increased levels of school trust and belonging.

\section{Key Differences Between Studies}

Although we found general agreement for the proposed model across both studies, there were discrepancies of note. A primary difference in the models estimated across Studies 1 and 2 was the direct and indirect makeup of the total effect of personal growth mindset beliefs on belonging. In Study 1, the entire total effect could be explained via indirect pathways through 
perceived peer mindset, perceived instructor mindset, and trust. Despite similarity in the zeroorder linear relationship between growth mindset and belonging (Study $1 r(909)=.16$; Study 2 $r(866)=.21)$, in Study 2, the total effect was comprised of both significant direct and indirect effects. Further, the direct effect itself seemed to account for the majority of the total variance in belonging explained by personal growth mindset. The reason for this difference in importance of perceived context may depend on the institution and its student culture. In the university in Study 1, students live on or near the campus, almost exclusively in housing with other students. They spend the majority of their time interacting with fellow students and professors in academic settings, with only $4 \%$ of the student populace registered as part-time. In the community college of Study 2, however, many students do not live on or near the campus, and $66 \%$ of them are enrolled as part-time students. It is likely that these markedly different environments carry implications for the role that peers' and instructors' mindsets play in the psychosocial experiences of students.

Another key difference across studies was the importance of gender for the outlined relationships. In Study 1, gender was a strong predictor of belonging, and many of the structural relationships among mindset, trust, and belonging variables differed meaningfully for women relative to men. In Study 2, gender seemed to play little to no role in the relationships specified by the model. These differences may have been observed for two reasons. First, as described above, the college context varies dramatically across the samples in Study 1 and Study 2. Gender-based identity threat may be more prevalent in the exclusive and competitive university setting of Study 1 than it is in Study 2. For example, the experience of stereotype threat - a form of social identity threat enacted due to negative group-based stereotypes (Steele \& Aronson, 1995) — worsens as academic identification increases (Steele, 1997). To the extent that those in 
selective university settings identify more strongly with their academics, they may be particularly susceptible to the deleterious effects of identity threat.

Second, not all STEM fields are equally threatening for individuals from underrepresented and stigmatized groups (Cheryan et al., 2017). For example, gaps in gender representation are much more pronounced in engineering than they are in mathematics (U.S. Department of Education, National Center for Education Statistics, 2019). The visible underrepresentation of women students (and faculty) in the engineering school (33\% of students in the engineering school in Study 1 were female, compared to $56 \%$ of the students in the school in Study 2) may invoke greater psychological threat (Boucher \& Murphy, 2017), which may restructure the relationships among mindsets, trust, and belonging for women relative to men.

A final note on the differences in these models: although gender does appear to moderate relationships in Study 1, in both studies, the model holds for all students. Even when controlling for gender — or even entirely removing women from the sample — the relationships are significant and the model continues to fit the data well. In the few studies investigating the relationships between objective cues, growth mindsets and belonging in higher education STEM settings, the relationships are seen only for women. For example, mindsets were found to support belonging for women but not men (Good et al., 2012; Rattan, Savani, Komarraju, Morrison, Boggs, \& Ambady, 2018), and stereotypical objects were found to undermine belonging for women but not men (e.g., Cheryan et al., 2009). In our model, mindsets are more broadly promotive of belonging because they inform subsequent perceptions of the context and inferences about the institution's value system, which are presumably important for all students.

\section{Limitations and Future Directions}


Although temporal order was established in Study 2, all data reported in this paper are correlational, and thus cannot be used to draw causal conclusions. Future research should derive specific hypotheses from this model to test experimentally in both laboratory and field settings. For example, a growth mindset intervention could be administered in a randomized controlled trial directly to undergraduate STEM students, and their perceptions of their peers' mindsets, instructors' mindsets, school trust, and belonging could be tracked over time.

Alternatively, given the importance of perceived instructor mindset beliefs to belongingness (and the problematic deficit lens implied by direct-to-student interventions), a program in which instructors are trained to develop and communicate their own growth mindset beliefs to students could be tested in a field experiment. The professors' students could then report their subsequent trust and belonging in order to assess the causal role that perceptions of instructors' mindsets may play in the development of a sense of belonging. Preliminary evidence suggests that experimental manipulations of professors' fixed mindset beliefs yield a lower sense of anticipated belonging in a laboratory setting (Muenks, Canning, LaCosse, Green, Zirkel, Garcia, \& Murphy, 2020). This research may be advanced by implementing and evaluating a field intervention to boost instructors' mindsets and examine the downstream effects on students' school trust and belonging.

Another limitation of the present work is that the number of covarying features from Study 1 to Study 2 confound any direct claims about the drivers of model generalizability. As mentioned previously, there are meaningful differences in postsecondary context and data collection that may account for the noted differences in model fit and estimated parameter values. As such, future studies should aim to vary one feature at a time, e.g., collecting and comparing a longitudinal sample of engineering students at a selective research university to a 
longitudinal sample of students at a broad-access college. In this case, the feature of interest would be the university setting, and it would not be confounded by the schedule of data collection (cross-sectional versus longitudinal).

Future directions of this research include the identification and investigation of additional contextual features that may be filtered through the lens of students' psychological mindsets. Relatedly, the role of the mindsets of others - peers, professors, school administrators, etc.should continue to be explored, especially how they interact dynamically with students' own mindsets. As these processes are illuminated, targeted change efforts can be carefully designed, enacted, and evaluated in efforts to promote students' belonging and well-being in STEM programs. By shifting the focus of these efforts to the environment—as opposed to targeting students themselves - the potential to drive sustainable structural change in higher education may be realized. As a result, national efforts to expand the STEM workforce may be complemented by a better understanding of how to support those students' and workers' wellbeing throughout the process. 


\section{Declarations}

\section{Funding}

No funding was received to assist with the preparation of this manuscript.

\section{Conflicts of Interest}

The authors have no relevant financial or non-financial interests to disclose.

\section{Ethics Approval}

Each study was approved by the institutional review board of the affiliated institution.

\section{Consent}

All study participants provided informed consent prior to responding to surveys or having their school records collected.

\section{Availability of Data and Material}

Deidentified data and materials will be made available by the researchers upon request.

\section{Code Availability}

Code will be made available by the researchers upon request. 


\section{References}

Allen, K., Kern, M. L., Vella-Brodrick, D., Hattie, J., \& Waters, L. (2018). What schools need to know about fostering school belonging: A meta-analysis. Educational Psychology Review, 30(1), 1-34. https://doi.org/10.1007/s10648-016-9389-8

ABET. (2020). Accreditation criteria \& supporting documents. https://www.abet.org/accreditation/accreditation-criteria/

Baumeister, R. F., Bratslavsky, E., Finkenauer, C., \& Vohs, K. D. (2001). Bad is stronger than good. Review of General Psychology, 5(4), 323-370. https://doi.org/10.1037/10892680.5.4.323

Blackwell, L. S., Trzesniewski, K. H., \& Dweck, C. S. (2007). Implicit theories of intelligence predict achievement across an adolescent transition: A longitudinal study and an intervention. Child Development, 78(1), 246-263. https://doi.org/10.1111/j.14678624.2007.00995.x

Boucher, K. L., \& Murphy, M. C. (2017). Why so few? The role of social identity and situational cues in understanding the underrepresentation of women in STEM fields. In K. I. Mavor, M. J. Platow, \& B. Bizumic (Eds.), Self and social identity in educational contexts (pp. 93111). Routledge/Taylor \& Francis Group.

Cabrera, A. F., Nora, A., Terenzini, P. T., Pascarella, E., \& Hagedorn, L. S. (1999). Campus racial climate and the adjustment of students to college. The Journal of Higher Education, 70(2), 134-160. https://doi.org/10.1080/00221546.1999.11780759

Cadinu, M., Maass, A., Rosabianca, A., \& Kiesner, J. (2005). Why do women underperform under stereotype threat? Evidence for the role of negative thinking. Psychological Science, 16(7), 572-578. https://doi.org/10.1111/j.0956-7976.2005.01577.x 
Canning, E. A., Harackiewicz, J. M., Priniski, S. J., Hecht, C. A., Tibbetts, Y., \& Hyde, J. S. (2018). Improving performance and retention in introductory biology with a utility-value intervention. Journal of Educational Psychology, 110(6), 834-849. https://doi.org/10.1037/edu0000244

Canning, E. A., Muenks, K., Green, D. J., \& Murphy, M. C. (2019). STEM faculty who believe ability is fixed have larger racial achievement gaps and inspire less student motivation in their classes. Science Advances, 5(2), 4734-4749. https://doi.org/10.1126/sciadv.aau4734

Canning, E. A., Murphy, M. C., Emerson, K. T. U., Chatman, J. A., Dweck, C. S., \& Kray, L. J. (2020). Cultures of genius at work: Organizational mindsets predict cultural norms, trust, and commitment. Personality and Social Psychology Bulletin, 46(4), 626-642. https://doi.org/10.1177/0146167219872473

Casad, B. J., Petzel, Z. W., \& Ingalls, E. A. (2019). A model of threatening academic environments predicts women STEM majors' self-esteem and engagement in STEM. Sex Roles, 80(7-8), 469-488. https://doi.org/10.1007/s11199-018-0942-4

Chambers, J. R., Epley, N., Savitsky, K., \& Windschitl, P. D. (2008). Knowing too much: Using private knowledge to predict how one is viewed by others. Psychological Science, 19(6), 542-548. https://doi.org/10.1111/j.1467-9280.2008.02121.x

Chavous, T. M. (2005). An intergroup contact-theory framework for evaluating racial climate on predominantly white college campuses. American Journal of Community Psychology, 36(34), 239-257. https://doi.org/10.1007/s10464-005-8623-1

Cheryan, S., Drury, B. J., \& Vichayapai, M. (2013). Enduring influence of stereotypical computer science role models on women's academic aspirations. Psychology of Women Quarterly, 37(1), 72-79. https://doi.org/10.1177/0361684312459328 
Cheryan, S., Meltzoff, A. N., \& Kim, S. (2011). Classrooms matter: The design of virtual classrooms influences gender disparities in computer science classes. Computers and Education, 57(2), 1825-1835. https://doi.org/10.1016/j.compedu.2011.02.004

Cheryan, S., Plaut, V. C., Davies, P. G., \& Steele, C. M. (2009). Ambient belonging: How stereotypical cues impact gender participation in computer science. Journal of Personality and Social Psychology, 97(6), 1045-1060. https://doi.org/10.1037/a0016239

Cheryan, S., Ziegler, S. A., Montoya, A. K., \& Jiang, L. (2017). Why are some STEM fields more gender balanced than others? Psychological Bulletin, 143(1), 1-35. https://doi.org/10.1037/bul0000052

Cohen, G. L., \& Garcia, J. (2008). Identity, belonging, and achievement. Current Directions in Psychological Science, 17(6), 365-369. https://doi.org/10.1111/j.1467-8721.2008.00607.x

Cohen, G. L., Steele, C. M., \& Ross, L. D. (1999). The mentor's dilemma: Providing critical feedback across the racial divide. Personality and Social Psychology Bulletin, 25(10), 1302-1318. https://doi.org/10.1177/0146167299258011

Cole, D. A., \& Preacher, K. J. (2014). Manifest variable path analysis: Potentially serious and misleading consequences due to uncorrected measurement error. Psychological Methods, 19(2), 300-315. https://doi.org/10.1037/a0033805

Critcher, C. R., \& Dunning, D. (2009). Egocentric pattern projection: How implicit personality theories recapitulate the geography of the self. Journal of Personality and Social Psychology, 97(1), 1-16. https://doi.org/10.1037/a0015670

Davies, P. G., Spencer, S. J., Quinn, D. M., \& Gerhardstein, R. (2002). Consuming images: How television commercials that elicit stereotype threat can restrain women academically and professionally. Personality and Social Psychology Bulletin, 28(12), 1615-1628. 
https://doi.org/10.1177/014616702237644

Dweck, C. S. (1999). Self-theories: Their role in motivation, personality, and development. Philadelphia: Psychology Press.

Dweck, C. S., Chiu, C.-y., \& Hong, Y.-y. (1995). Implicit theories and their role in judgments and reactions: A world from two perspectives. Psychological Inquiry, 6(4), 267-285. https://doi.org/10.1207/s15327965pli0604_1

Dweck, C. S., \& Leggett, E. L. (1988). A social-cognitive approach to motivation and personality. Psychological Review, 95(2), 256-273. https://doi.org/10.1037/0033295X.95.2.256

Eagan, M. K., Stolzenberg, E. B., Ramirez, J. J., Aragon, M. C., Suchard, M. R., \& Rios-Aguilar, C. (2016). The American freshman: Fifty-Year trends, 1966-2015. Los Angeles: Higher Education Research Institute, UCLA. Retrieved from https://www.heri.ucla.edu/monographs/50YearTrendsMonograph2016.pdf

Eaton, A. A., Saunders, J. F., Jacobson, R. K., \& West, K. (2020). How gender and race stereotypes impact the advancement of scholars in STEM: Professors' biased evaluations of physics and biology post-doctoral candidates. Sex Roles, 82, 127-141. https://doi.org/10.1007/s11199-019-01052-w

Emerson, K. T. U., \& Murphy, M. C. (2014). Identity threat at work: How social identity threat and situational cues contribute to racial and ethnic disparities in the workplace. Cultural Diversity and Ethnic Minority Psychology, 20(4), 508-520. https://doi.org/10.1037/a0035403

Epley, N., \& Eyal, T. (2019). Through a looking glass, darkly: Using mechanisms of mind perception to identify accuracy, overconfidence, and underappreciated means for 
improvement. In J. M. Olson (Ed.) Advances in experimental social psychology (Vol. 60, pp. 65-120). Academic Press. https://doi.org/10.1016/bs.aesp.2019.04.002

Epley, N., Keysar, B., Van Boven, L., \& Gilovich, T. (2004). Perspective taking as egocentric anchoring and adjustment. Journal of Personality and Social Psychology, 87(3), 327-339. doi:10.1037/0022-3514.87.3.327

Epley, N., \& Waytz, A. (2010). Mind perception. In S. T. Fiske, D. T. Gilbert, \& G. Lindzey (Eds.), Handbook of social psychology (pp. 498-541). John Wiley \& Sons, Inc.. https://doi.org/10.1002/9780470561119.socpsy001014

Felder, R. M., Brent, R., \& Prince, M. J. (2013). Engineering instructional development: programs, best practices, and recommendations. Journal of Engineering Education, 100(1), 89-122. https://doi.org/10.1002/j.2168-9830.2011.tb00005.x

Freeman, T. M., Anderman, L. H., \& Jensen, J. M. (2007). Sense of belonging in college freshmen at the classroom and campus levels. Journal of Experimental Education, 75(3), 203-220. https://doi.org/10.3200/JEXE.75.3.203-220

Giffi, C., Wellener, P., Dollar, B., Ashton, H., Monck, L., \& Moutray, C. (2018). The jobs are here, but where are the people? Key findings from the 2018 Deloitte and The Manufacturing Institute skills gap and future of work study. Retrieved from Deloitte website: https://www2.deloitte.com/us/en/insights/industry/manufacturing/manufacturingskills-gap-study.html

Good, C., Rattan, A., \& Dweck, C. S. (2012). Why do women opt out? Sense of belonging and women's representation in mathematics. Journal of Personality and Social Psychology, 102(4), 700-717. https://doi.org/10.1037/a0026659

Goodenow, C., \& Grady, K. E. (1993). The relationship of school belonging and friends' values 
to academic motivation among urban adolescent students. Journal of Experimental Education, 62(1), 60-71. https://doi.org/10.1080/00220973.1993.9943831

Gopalan, M., \& Brady, S. T. (2020). College students' sense of belonging: A national perspective. Educational Researcher, 49(2), 134-137. https://doi.org/10.3102/0013189X19897622

Gummadam, P., Pittman, L. D., \& Ioffe, M. (2016). School belonging, ethnic identity, and psychological adjustment among ethnic minority college students. The Journal of Experimental Education, 84(2), 289-306. https://doi.org/10.1080/00220973.2015.1048844

Han, C. W., Farruggia, S. P., \& Moss, T. P. (2017). Effects of academic mindsets on college students' achievement and retention. Journal of College Student Development, 58(8), 11191134. https://doi.org/10.1353/csd.2017.0089

Haselhuhn, M. P., Schweitzer, M. E., \& Wood, A. M. (2010). How implicit beliefs influence trust recovery. Psychological Science, 21(5), 645-648. https://doi.org/10.1177/0956797610367752

Hausmann, L. R., Schofield, J. W., \& Woods, R. L. (2007). Sense of belonging as a predictor of intentions to persist among African American and White first-year college students. Research in Higher Education, 48(7), 803-839. https://doi.org/10.1007/s11162007-9052-9

Hong, Y.-y., Dweck, C. S., Chiu, C.-y., Lin, D. M.-S., \& Wan, W. (1999). Implicit theories, attributions, and coping: A meaning system approach. Journal of Personality and Social Psychology, 77(3), 588-599. https://doi.org/10.1037/0022-3514.77.3.588

Hu, L. T., \& Bentler, P. M. (1999). Cutoff criteria for fit indexes in covariance structure analysis: Conventional criteria versus new alternatives. Structural Equation Modeling, 6(1), 1-55. 
https://doi.org/10.1080/10705519909540118

Hurtado, S., \& Carter, D. F. (1997). Effects of college transition and perceptions of the campus racial climate on Latino college students' sense of belonging. Sociology of Education, 70(4), 324-345. https://doi.org/10.2307/2673270

Hurtado, S., Clayton-Pedersen, A. R., Allen, W. R., \& Milem, J. F. (1998). Enhancing campus climates for racial/ethnic diversity: Educational policy and practice. The Review of Higher Education 21(3), 279-302. doi:10.1353/rhe.1998.0003.

Johns, M., Inzlicht, M., \& Schmader, T. (2008). Stereotype Threat and Executive Resource Depletion: Examining the Influence of Emotion Regulation. Journal of Experimental Psychology: General, 137(4), 691-705. https://doi.org/10.1037/a0013834

Kenny, D. A., \& DePaulo, B. M. (1993). Do people know how others view them? An empirical and theoretical account. Psychological Bulletin, 114(1), 145-161. https://doi.org/10.1037/0033-2909.114.1.145

King, B. (2016). Does postsecondary persistence in STEM vary by gender? AERA Open, 2(4), 110. https://doi.org/10.1177/2332858416669709

Lewis, K. L., \& Hodges, S. D. (2015). Expanding the concept of belonging in academic domains: Development and validation of the Ability Uncertainty Scale. Learning and Individual Differences, 37, 197-202. https://doi.org/10.1016/j.lindif.2014.12.002

Lipson, S. K., Zhou, S., Wagner, B., Beck, K., \& Eisenberg, D. (2016). Major differences: variations in undergraduate and graduate student mental health and treatment utilization across academic disciplines. Journal of College Student Psychotherapy, 30(1), 23-41. https://doi.org/10.1080/87568225.2016.1105657

Lyubomirsky, S., King, L., \& Diener, E. (2005). The benefits of frequent positive affect: Does 
happiness lead to success? Psychological Bulletin, 131(6), 803-855.

https://doi.org/10.1037/0033-2909.131.6.803

Maruyama, G. M. (1998). Basics of structural equation modeling. Sage Publications, Inc.

https://doi.org/10.4135/9781483345109

McArdle, J. J., \& McDonald, R. P. (1984). Some algebraic properties of the Reticular Action Model for moment structures. British Journal of Mathematical and Statistical Psychology, 37(2), 234-251. https://doi.org/10.1111/j.2044-8317.1984.tb00802.x

Mounts, N. S. (2004). Contributions of parenting and campus climate to freshmen adjustment in a multiethnic sample. Journal of Adolescent Research, 19(4), 468-491. https://doi.org/10.1177/0743558403258862

Muenks, K., Canning, E. A., LaCosse, J., Green, D. J., Zirkel, S., Garcia, J. A., \& Murphy, M. C. (2020). Does my professor think my ability can change? Students' perceptions of their STEM professors' mindset beliefs predict their psychological vulnerability, engagement, and performance in class. Journal of Experimental Psychology: General, 149(11), 21192144. https://doi.org/10.1037/xge0000763

Murphy, M. C., \& Dweck, C. S. (2016). Mindsets shape consumer behavior. Journal of Consumer Psychology, 26(1), 127-136. https://doi.org/10.1016/j.jcps.2015.06.005

Murphy, M. C., Steele, C. M., \& Gross, J. J. (2007). Signaling threat: How situational cues affect women in math, science, and engineering settings. Psychological Science, 18(10), 879-885. https://doi.org/10.1111/j.1467-9280.2007.01995.x

Musu-Gillette, L., de Brey, C., McFarland, J., Hussar, W., Sonnenberg, W., \& WilkinsonFlicker, S. (2017). Status and Trends in the Education of Racial and Ethnic Groups 2017 (NCES 2017-051). U.S. Department of Education, National Center for Education Statistics. 
Washington, DC. Retrieved from http://nces.ed.gov/pubsearch.

Neale, M. C., Hunter, M. D., Pritikin, J. N., Zahery, M., Brick, T. R., Kirkpatrick, R. M., Estabrook, R., Bates, T. C., Maes, H. H., \& Boker, S. M. (2016). OpenMx 2.0: Extended Structural Equation and Statistical Modeling. Psychometrika, 81(2), 535-549. https://doi.org/10.1007/s11336-014-9435-8

Nguyen, H.-H. D., \& Ryan, A. M. (2008). Does stereotype threat affect test performance of minorities and women? A meta-analysis of experimental evidence. Journal of Applied Psychology, 93(6), 1314-1334. https://doi.org/10.1037/a0012702

Nguyen, T.-H., \& Nguyen, B. M. D. (2018). Is the "first-generation student" term useful for understanding inequality? The role of intersectionality in illuminating the implications of an accepted-yet unchallenged - term. Review of Research in Education, 42(1), 146-176. https://doi.org/10.3102/0091732X18759280

Nickerson, R. S. (1998). Confirmation bias: A ubiquitous phenomenon in many guises. Review of General Psychology, 2(2), 175-220. https://doi.org/10.1037/1089-2680.2.2.175

Osterman, K. F. (2000). Students' need for belonging in the school community. Review of Educational Research, 70(3), 323-367. https://doi.org/10.3102/00346543070003323

Paunesku, D. (2019, July 9). The deficit lens of the 'achievement gap' needs to be flipped. Here's how. Education Week. https://www.edweek.org/ew/articles/2019/07/10/the-deficit-lens-ofthe-achievement-gap.html

Pittman, L. D., \& Richmond, A. (2007). Academic and psychological functioning in late adolescence: The importance of school belonging. Journal of Experimental Education, 75(4), 270-290. https://doi.org/10.3200/JEXE.75.4.270-292

President's Council of Advisors on Science and Technology, Executive Office of the President. 
(2012). Engage to excel: Producing one million additional college graduates with degrees in science, technology, engineering, and mathematics. Retrieved from https://files.eric.ed.gov/fulltext/ED541511.pdf

Purdie-Vaughns, V., Steele, C. M., Davies, P. G., Ditlmann, R., \& Crosby, J. R. (2008). Social identity contingencies: How diversity cues signal threat or safety for African Americans in mainstream institutions. Journal of Personality and Social Psychology, 94(4), 615-630. https://doi.org/10.1037/0022-3514.94.4.615

Rattan, A., Savani, K., Komarraju, M., Morrison, M. M., Boggs, C., \& Ambady, N. (2018). Meta-lay theories of scientific potential drive underrepresented students' sense of belonging to science, technology, engineering, and mathematics (STEM). Journal of Personality and Social Psychology, 115(1), 54-75. https://doi.org/10.1037/pspi0000130

Roeser, R. W., Midgley, C., \& Urdan, T. C. (1996). Perceptions of the school psychological environment and early adolescents' psychological and behavioral functioning in school: The mediating role of goals and belonging. Journal of Educational Psychology, 88(3), 408-422. https://doi.org/10.1037/0022-0663.88.3.408

Sarrasin, J. B., Nenciovici, L., Foisy, L. M. B., Allaire-Duquette, G., Riopel, M., \& Masson, S. (2018). Effects of teaching the concept of neuroplasticity to induce a growth mindset on motivation, achievement, and brain activity: A meta-analysis. In Trends in Neuroscience and Education (Vol. 12, pp. 22-31). Elsevier GmbH. https://doi.org/10.1016/j.tine.2018.07.003

Schafer, J. L., \& Graham, J. W. (2002). Missing data: Our view of the state of the art. Psychological Methods, 7(2), 147-177. https://doi.org/10.1037/1082-989X.7.2.147

Schmader, T., Johns, M., \& Forbes, C. (2008). An integrated process model of stereotype threat 
effects on performance. Psychological Review, 115(2), 336-356. https://doi.org/10.1037/0033-295X.115.2.336

Schreiber, J. B., Nora, A., Stage, F. K., Barlow, E. A., \& King, J. (2006). Reporting structural equation modeling and confirmatory factor analysis results: A review. The Journal of Educational Research, 99(6), 323-338. https://doi.org/10.3200/JOER.99.6.323-338

Settles, I. H., O’Connor, R. C., \& Yap, S. C. Y. (2016). Climate Perceptions and Identity Interference Among Undergraduate Women in STEM. Psychology of Women Quarterly, 40(4), 488-503. https://doi.org/10.1177/0361684316655806

Slaten, C. D., Ferguson, J. K., Allen, K.-A., Brodrick, D.-V., \& Waters, L. (2016). School belonging: A review of the history, current trends, and future directions. https://doi.org/10.1017/edp.2016.6

Spencer, S. J., Steele, C. M., \& Quinn, D. M. (1999). Stereotype threat and women's math performance. Journal of Experimental Social Psychology, 35(1), 4-28. https://doi.org/10.1006/jesp.1998.1373

Steele, C. M. (1997). A Threat in the Air: How Stereotypes Shape Intellectual Identity and Performance. American Psychologist, 52(6), 613-629. https://doi.org/10.1037/0003066X.52.6.613

Steele, C. M., \& Aronson, J. (1995). Stereotype Threat and the Intellectual Test Performance of African Americans. Journal of Personality and Social Psychology, 69(5), 797-811. https://doi.org/10.1037/0022-3514.69.5.797

Steele, C. M., Spencer, S. J., \& Aronson, J. (2002). Contending with group image: The psychology of stereotype and social identity threat. In M. P. Zanna (Ed.), Advances in experimental social psychology (Vol. 34, pp. 379-440). Academic Press. 
https://doi.org/10.1016/S0065-2601(02)80009-0

Strayhorn, T. L. (2012). Satisfaction and retention among African American men at two-year community colleges. Community College Journal of Research and Practice, 36(5), 358375. https://doi.org/10.1080/10668920902782508

Strayhorn, T. L. (2019). College students' sense of belonging: A key to educational success for all students (2 $2^{\text {nd }}$ ed.). Routledge.

Thoman, D. B., Smith, J. L., Brown, E. R., Chase, J., \& Lee, J. Y. K. (2013). Beyond performance: A motivational experiences model of stereotype threat. Educational Psychology Review, 25(2), 211-243. https://doi.org/10.1007/s10648-013-9219-1

U.S. Census Bureau (2018). Current Population Survey, School Enrollment Supplement. Retrieved from https://www.census.gov/library/visualizations/2018/comm/classroomdiversity.html

U.S. Department of Education, National Center for Education Statistics, Earned Degrees Conferred, 1949-50 and 1959-60; Higher Education General Information Survey (HEGIS), "Degrees and Other Formal Awards Conferred" surveys, 1969-70 through 1985-86; Integrated Postsecondary Education Data System (IPEDS), "Completions Survey" (IPEDSC:87-99); and IPEDS Fall 2000 through Fall 2018, Completions component. Retrieved from https://nces.ed.gov/programs/digest/d19/tables/dt19_325.45.asp?current=yes

U.S. Bureau of Labor Statistics, "Employed persons by detailed occupation, sex, race, and Hispanic or Latino ethnicity," Labor Force Statistics from the Current Population Survey, Table 11, 2019. Retrieved from https://www.bls.gov/cps/cpsaat11.htm Voelkl, K. E. (1996). Measuring Students' Identification with School. Educational and Psychological Measurement, 56(5), 760-770. 
https://doi.org/10.1177/0013164496056005003

Walton, G. M., \& Brady, S. T. (2017). The many questions of belonging. In A. J. Elliot, C. S. Dweck, \& D. S. Yeager (Eds.), Handbook of competence and motivation: Theory and application (pp. 272-293). The Guilford Press.

Walton, G. M. \& Brady, S. T. (2020). The social-belonging intervention. To appear in G. M. Walton \& A. J. Crum (Eds.), Handbook of wise interventions: How social-psychological insights can help solve problems (pp. 1-47). Guilford Press: New York, NY.

Walton, G. M., \& Cohen, G. L. (2007). A question of belonging: Race, social fit, and achievement. Journal of Personality and Social Psychology, 92(1), 82-96. https://doi.org/10.1037/0022-3514.92.1.82

Walton, G. M., \& Cohen, G. L. (2011). A brief social-belonging intervention improves academic and health outcomes of minority students. Science, 331(6023), 1447-1451. https://doi.org/10.1126/science.1198364

Walton, G. M., Logel, C., Peach, J. M., Spencer, S. J., \& Zanna, M. P. (2015). Two brief interventions to mitigate a "chilly climate" transform women's experience, relationships, and achievement in engineering. Journal of Educational Psychology, 107(2), 468-485. http://dx.doi.org/10.1037/a0037461468

Wang, M.-T., \& Degol, J. (2017). Gender gap in science, technology, engineering, and mathematics (STEM): Current knowledge, implications for practice, policy, and future directions. Educational Psychology Review, 29(1), 119-140. https://doi.org/10.1007/s10648-015-9355-x

Xue, Y., \& Larson, R. C. (2015). STEM crisis or STEM surplus? Yes and yes. Retrieved from U.S. Bureau of Labor Statistics: https://doi.org/10.21916/mlr.2015.14. 
Yeager, D., Bryk, A., Hausman, H., Muhich, J., \& Morales, L. (2013). Practical measurement. Unpublished manuscript.

Yeager, D. S., Purdie-Vaughns, V., Garcia, J., Apfel, N., Brzustoski, P., Master, A., Hessert, W. T., Williams, M. E., \& Cohen, G. L. (2014). Breaking the cycle of mistrust: Wise interventions to provide critical feedback across the racial divide. Journal of Experimental Psychology: General, 143(2), 804-824. https://doi.org/10.1037/a0033906

Yeager, D. S., Purdie-Vaughns, V., Hooper, S. Y., \& Cohen, G. L. (2017). Loss of institutional trust among racial and ethnic minority adolescents: A consequence of procedural injustice and a cause of life-span outcomes. Child Development, 88(2), 658-676. https://doi.org/10.1111/cdev.12697 


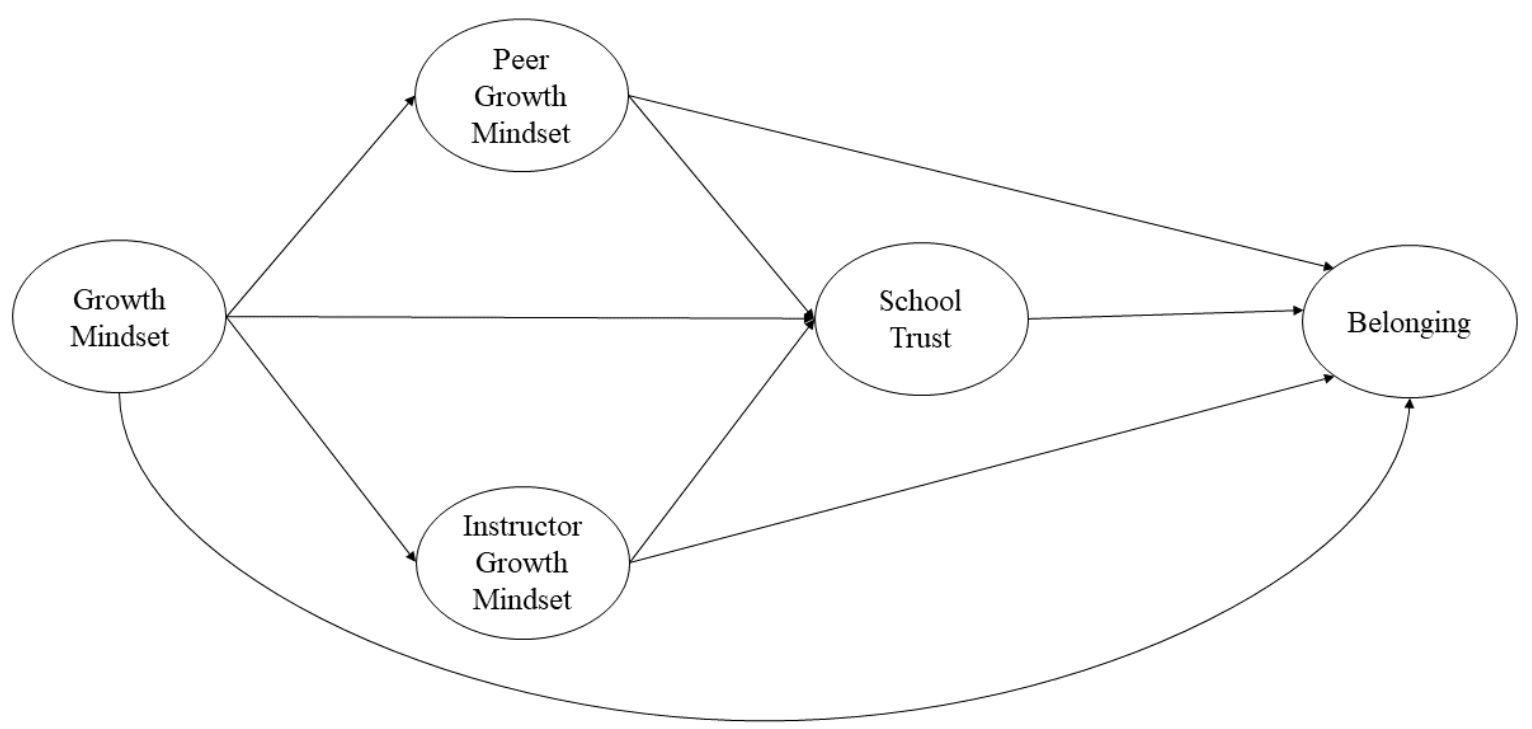

Fig. 1 Theoretical model depicting hypothesized relationships among personal growth mindset, perceived peer growth mindset, perceived instructor growth mindset, school trust, and belonging 
Table 1

Descriptive Summary of Key Variables

\begin{tabular}{|c|c|c|c|c|c|c|c|c|}
\hline & \multicolumn{4}{|c|}{ Study 1} & \multicolumn{4}{|c|}{ Study 2} \\
\hline & \multirow[b]{2}{*}{ M } & \multirow[b]{2}{*}{ SD } & \multicolumn{2}{|c|}{ Rescaled $[0,1]$} & \multirow[b]{2}{*}{ M } & \multirow[b]{2}{*}{ SD } & \multicolumn{2}{|c|}{ Rescaled $[0,1]$} \\
\hline & & & M & $\mathrm{SD}$ & & & M & SD \\
\hline Growth mindset & 3.86 & 0.88 & 0.48 & 0.15 & 3.86 & 1.24 & 0.71 & 0.31 \\
\hline Peer growth mindset & 3.69 & 1.06 & 0.45 & 0.18 & 3.08 & 0.80 & 0.52 & 0.20 \\
\hline Instructor growth mindset & 3.63 & 0.87 & 0.44 & 0.14 & 3.99 & 0.53 & 0.47 & 0.13 \\
\hline School trust & 6.06 & 0.99 & 0.73 & 0.17 & 4.17 & 0.74 & 0.79 & 0.18 \\
\hline Belonging & 5.05 & 0.98 & 0.59 & 0.16 & 3.56 & 0.90 & 0.64 & 0.22 \\
\hline
\end{tabular}

Note. Study $1 N=957$. Study $2 N=2083$. 
Table 2

Study 1 OLS Regression Predicting Belonging

\begin{tabular}{|c|c|c|c|c|}
\hline & \multirow{2}{*}{$\frac{\text { Model } 1}{\beta}$} & \multirow{2}{*}{$\frac{\text { Model } 2}{\beta}$} & \multicolumn{2}{|c|}{ Model 3} \\
\hline & & & $\beta$ & $95 \% \mathrm{CI}$ \\
\hline Growth mindset & $0.17 * * *$ & $0.08 *$ & $0.07 *$ & {$[0.01,0.13]$} \\
\hline Peer growth mindset & & 0.04 & $0.08^{*}$ & {$[0.01,0.15]$} \\
\hline Instructor growth mindset & & $0.22 * * *$ & $0.08 *$ & {$[0.01,0.16]$} \\
\hline School trust & & & $0.36 * * *$ & {$[0.30,0.42]$} \\
\hline \multicolumn{5}{|l|}{ Controls } \\
\hline First generation & 0.09 & 0.08 & 0.12 & {$[-0.09,0.34]$} \\
\hline Low-income & $-0.34 * *$ & $-0.38 * * *$ & $-0.28 * *$ & {$[-0.47,-0.08]$} \\
\hline URM & -0.02 & 0.01 & 0.11 & {$[-0.08,0.30]$} \\
\hline Female & $-0.17 * *$ & $-0.13 *$ & $-0.15^{*}$ & {$[-0.27,-0.03]$} \\
\hline High school achievement & $0.11 * *$ & $0.10 * *$ & $0.11 * *$ & {$[0.04,0.17]$} \\
\hline Intercept & $0.13 *$ & $0.11 *$ & 0.09 & {$[0.00,0.18]$} \\
\hline Adj. $R^{\wedge} 2$ & 0.06 & 0.11 & & 0.22 \\
\hline
\end{tabular}

Note. $N=890$. URM = underrepresented racial-ethnic minority. $\mathrm{CI}=$ confidence interval.

Regression coefficients are standardized.

$* p<.05 . * * p<.01 . * * * p<.001$. 
Table 3

Final OLS Regression Models with Significant Interaction Terms Predicting Belonging

\begin{tabular}{|c|c|c|c|c|}
\hline & \multicolumn{2}{|c|}{ Study 1} & \multicolumn{2}{|c|}{ Study 2} \\
\hline & $\beta$ & $95 \% \mathrm{CI}$ & $\beta$ & $95 \% \mathrm{CI}$ \\
\hline Growth mindset & $0.07 *$ & {$[0.002,0.13]$} & $0.11 * *$ & {$[0.04,0.17]$} \\
\hline Peer growth mindset & 0.03 & {$[-0.06,0.11]$} & 0.01 & {$[-0.06,0.08]$} \\
\hline Instructor growth mindset & $0.08^{*}$ & {$[0.01,0.16]$} & $-0.21 * * *$ & {$[-0.33,-0.10]$} \\
\hline School trust & $0.36 * * *$ & {$[0.30,0.43]$} & $0.55 * * *$ & {$[0.49,0.62]$} \\
\hline Peer growth mindset $\mathrm{x}$ female & $0.13 *$ & {$[0.01,0.24]$} & & \\
\hline Instructor growth mindset $x$ female & & & $0.22 * *$ & {$[0.07,0.36]$} \\
\hline \multicolumn{5}{|l|}{ Controls } \\
\hline First generation & 0.12 & {$[-0.10,0.33]$} & 0.00 & {$[-0.13,0.13]$} \\
\hline Low-income & $-0.27 * *$ & {$[-0.46,-0.08]$} & -0.04 & {$[-0.25,0.17]$} \\
\hline URM & 0.11 & {$[-0.08,0.30]$} & 0.00 & {$[-0.13,0.13]$} \\
\hline Female & $-0.15^{* *}$ & {$[-0.27,-0.03]$} & -0.07 & {$[-0.21,0.07]$} \\
\hline High school achievement & $0.11 * * *$ & {$[0.05,0.18]$} & 0.03 & {$[-0.04,0.09]$} \\
\hline Intercept & 0.09 & {$[-0.002,0.18]$} & 0.14 & {$[-0.02,0.30]$} \\
\hline Adj. $R^{\wedge} 2$ & & 0.22 & & 0.35 \\
\hline
\end{tabular}

Note. Study $1 N=890$. Study $2 N=602$. URM = underrepresented racial-ethnic minority. $\mathrm{CI}=$ confidence interval. Regression coefficients for continuous variables are standardized.

$* p<.05 . * * p<.01 . * * * p<.001$. 


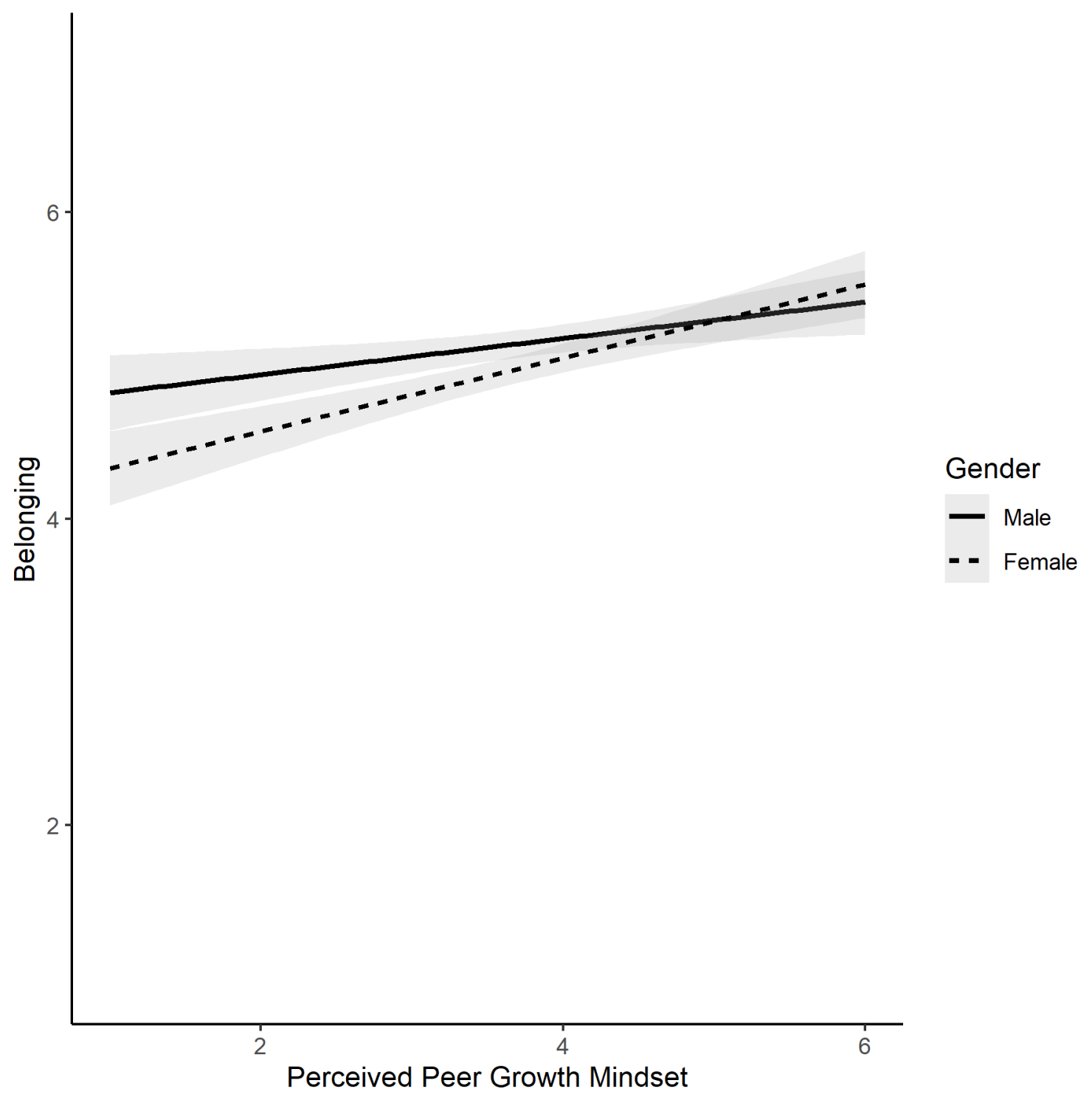

Fig. 2 Interaction between perceived peer growth mindset and gender on belonging for participants in Study 1 . Values represent raw scores. Shaded bands are $95 \%$ confidence intervals 


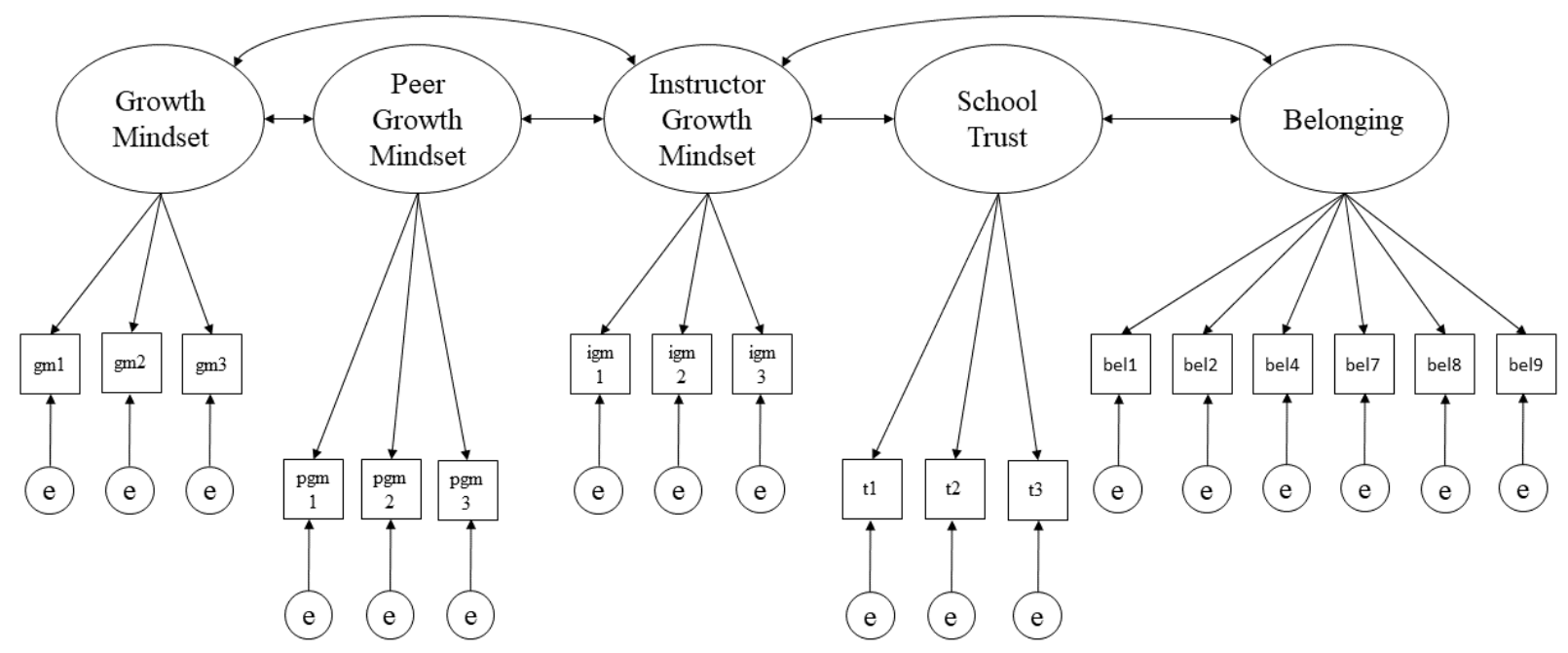

Fig. 3 Study 1 confirmatory factor analysis. Variances of the factors are fixed to 1. Parameter estimates are in Table S3 in Online Resource 2. Comparative fit index $=0.93$, Tucker-Lewis Index $=0.92$, root mean square error of approximation $=0.065,95 \% \mathrm{CI}[0.059,0.071] . \mathrm{e}=$ error. The Belonging latent variable does not contain all 10 indicators due to poor loadings and/or unexpected cross-loadings of the other indicators (see Online Resource 1) 


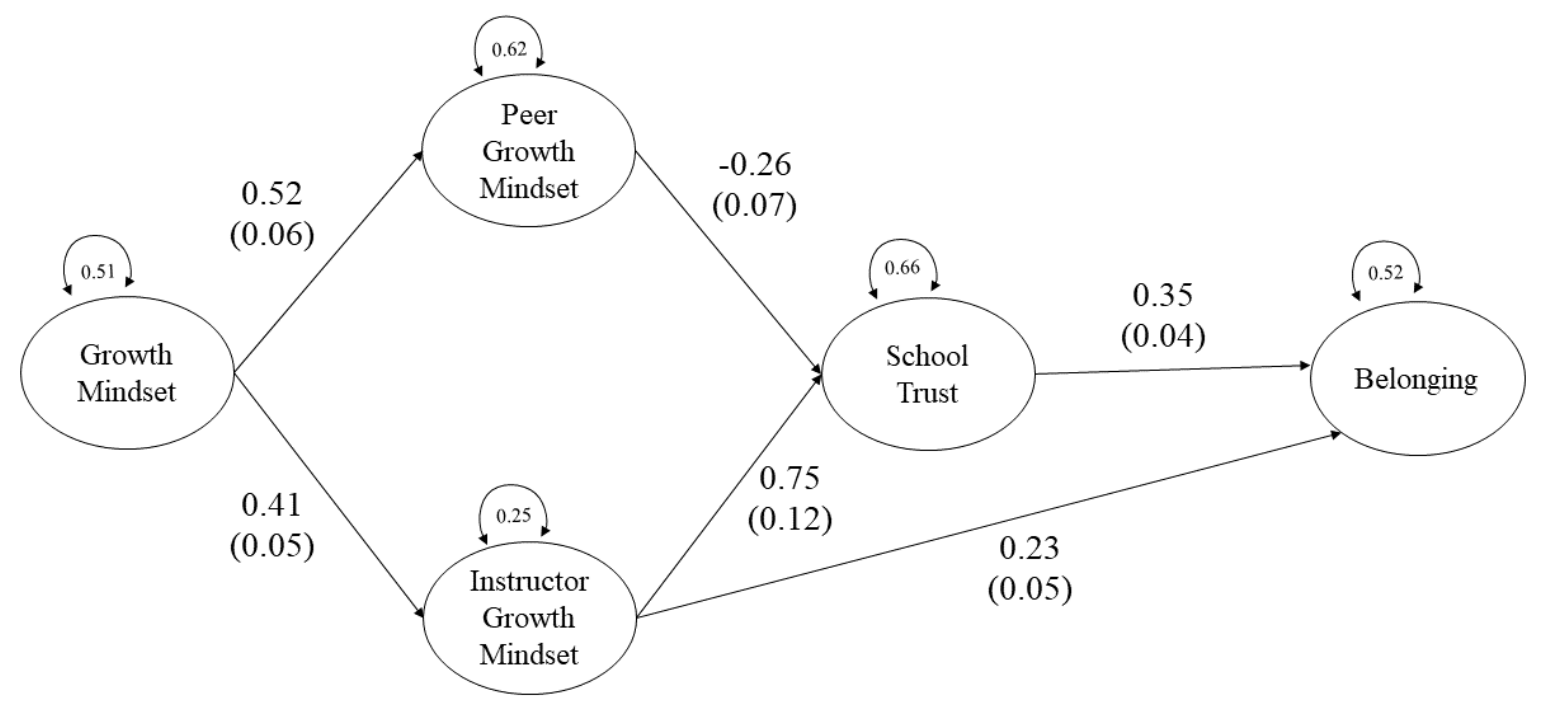

Fig. 4 Final empirical model after pruning and estimation for Study 1. Missing paths were nonsignificant and removed from the model for parsimony and to improve model fit (root mean square error of approximation). Path estimates are in standard deviation units (SEs in parentheses). All paths are significant $p<.001$. The model controls for first generation status, low-income status, underrepresented racial-ethnic minority status, and gender by specifying paths from each covariate to each latent variable. $R^{2}=.22, \mathrm{CFI}=0.93, \mathrm{TLI}=0.90, \mathrm{RMSEA}=$ $0.056,95 \%$ CI $[0.053,0.063]$ 


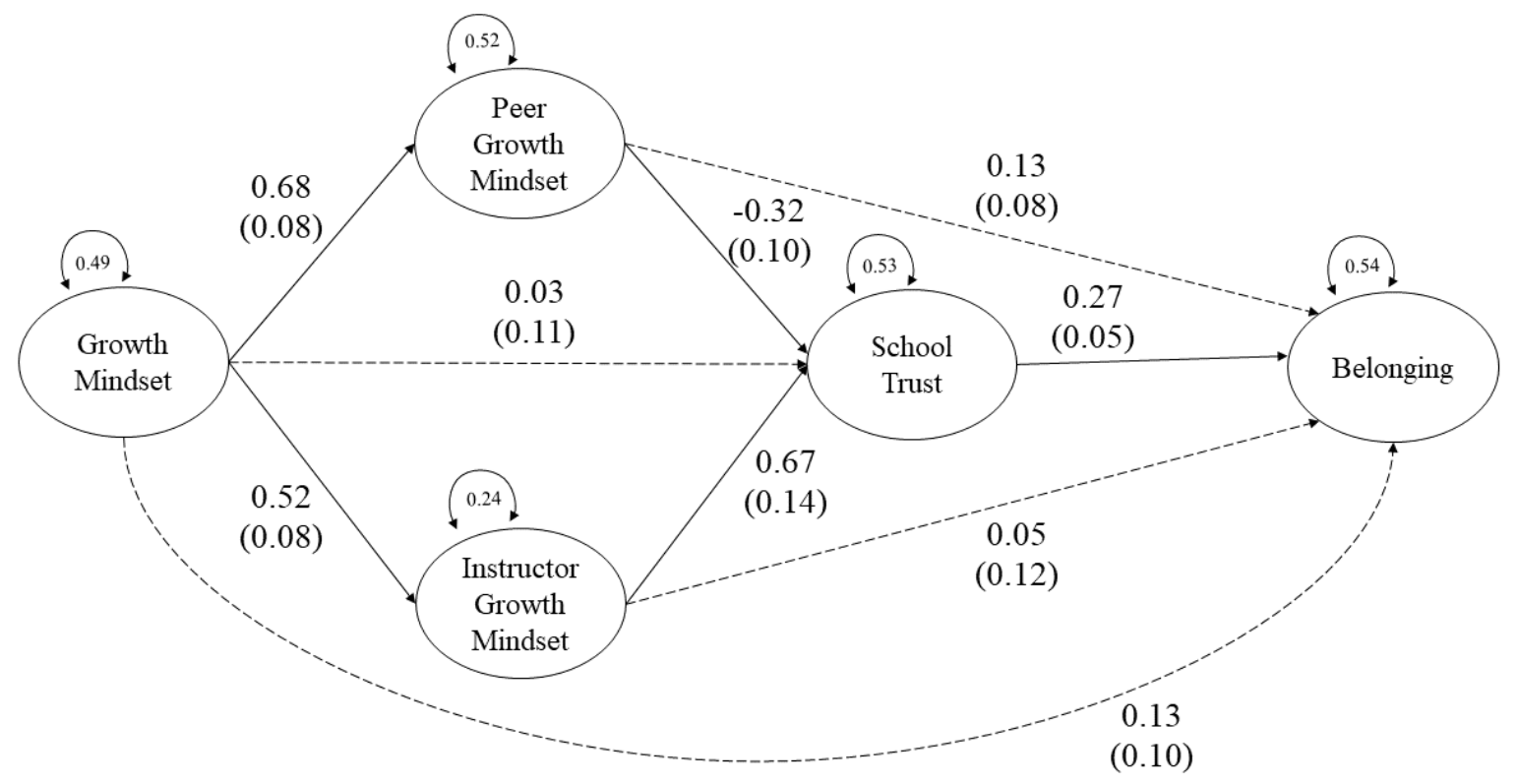

Fig. 5 Full empirical model parameter estimates for women in Study 1. The estimates displayed are the result of a multigroup model in which all parameters between gender groups were allowed to vary. Path estimates are in standard deviation units (SEs in parentheses). All solid-line paths are significant $p<.001$. All dashed-line paths are not significant $(p>.05)$. The model controls for first generation status, low-income status, and underrepresented racial-ethnic minority status by specifying paths from each covariate to each latent variable. $\mathrm{CFI}=0.92$, TLI $=$ $0.90, \mathrm{RMSEA}=0.044,95 \%$ CI $[0.040,0.048]$ 


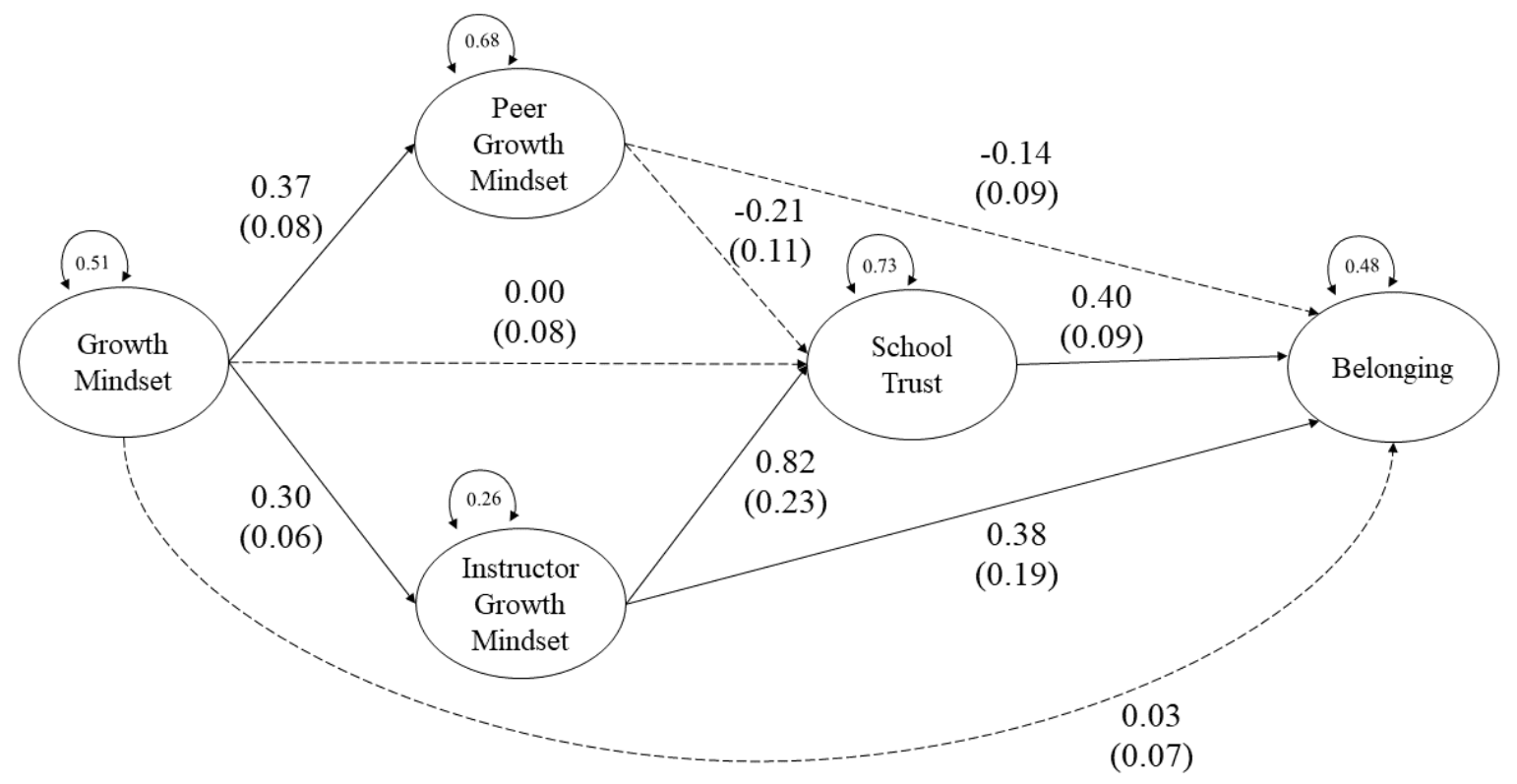

Fig. 6 Full empirical model parameter estimates for men in Study 1. The estimates displayed are the result of a multigroup model in which all parameters between gender groups were allowed to vary. Path estimates are in standard deviation units (SEs in parentheses). All solid-line paths are significant $p<.001$, except Instructor Growth Mindset to Belonging, $p=.048$. All dashed-line paths are not significant $(p>.05)$. The model controls for first generation status, low-income status, and underrepresented racial-ethnic minority status by specifying paths from each covariate to each latent variable. $\mathrm{CFI}=0.92, \mathrm{TLI}=0.90, \mathrm{RMSEA}=0.044,95 \% \mathrm{CI}[0.040$, $0.048]$ 
Table 4

Study 2 OLS Regression Predicting Belonging

\begin{tabular}{|c|c|c|c|c|}
\hline & \multirow{2}{*}{$\frac{\text { Model } 1}{\beta}$} & \multirow{2}{*}{$\frac{\text { Model } 2}{\beta}$} & \multicolumn{2}{|c|}{ Model 3} \\
\hline & & & $\beta$ & $95 \% \mathrm{CI}$ \\
\hline Growth mindset & $0.20 * * *$ & $0.18 * * *$ & $0.11 * * *$ & {$[0.04,0.18]$} \\
\hline Peer growth mindset & & 0.02 & 0.01 & {$[-0.06,0.08]$} \\
\hline Instructor growth mindset & & 0.04 & -0.08 & {$[-0.15,0.00]$} \\
\hline School trust & & & $0.55 * * *$ & {$[0.49,0.62]$} \\
\hline \multicolumn{5}{|l|}{ Controls } \\
\hline First generation & -0.03 & -0.02 & 0.00 & {$[-0.13,0.13]$} \\
\hline Low-income & -0.14 & -0.14 & -0.05 & {$[-0.27,0.16]$} \\
\hline URM & -0.07 & -0.07 & 0.00 & {$[-0.14,0.13]$} \\
\hline Female & -0.06 & -0.07 & -0.06 & {$[-0.20,0.08]$} \\
\hline High school achievement & 0.05 & 0.05 & 0.03 & {$[-0.03,0.09]$} \\
\hline Intercept & $0.21 *$ & $0.21 *$ & 0.15 & {$[-0.01,0.31]$} \\
\hline Adj. $R^{\wedge} 2$ & 0.04 & 0.04 & & 0.34 \\
\hline
\end{tabular}

Note. $N=602$. URM $=$ underrepresented racial-ethnic minority. $\mathrm{CI}=$ confidence interval.

Regression coefficients are standardized.

$* p<.05$. ** $p<.01$. *** $p<.001$. 


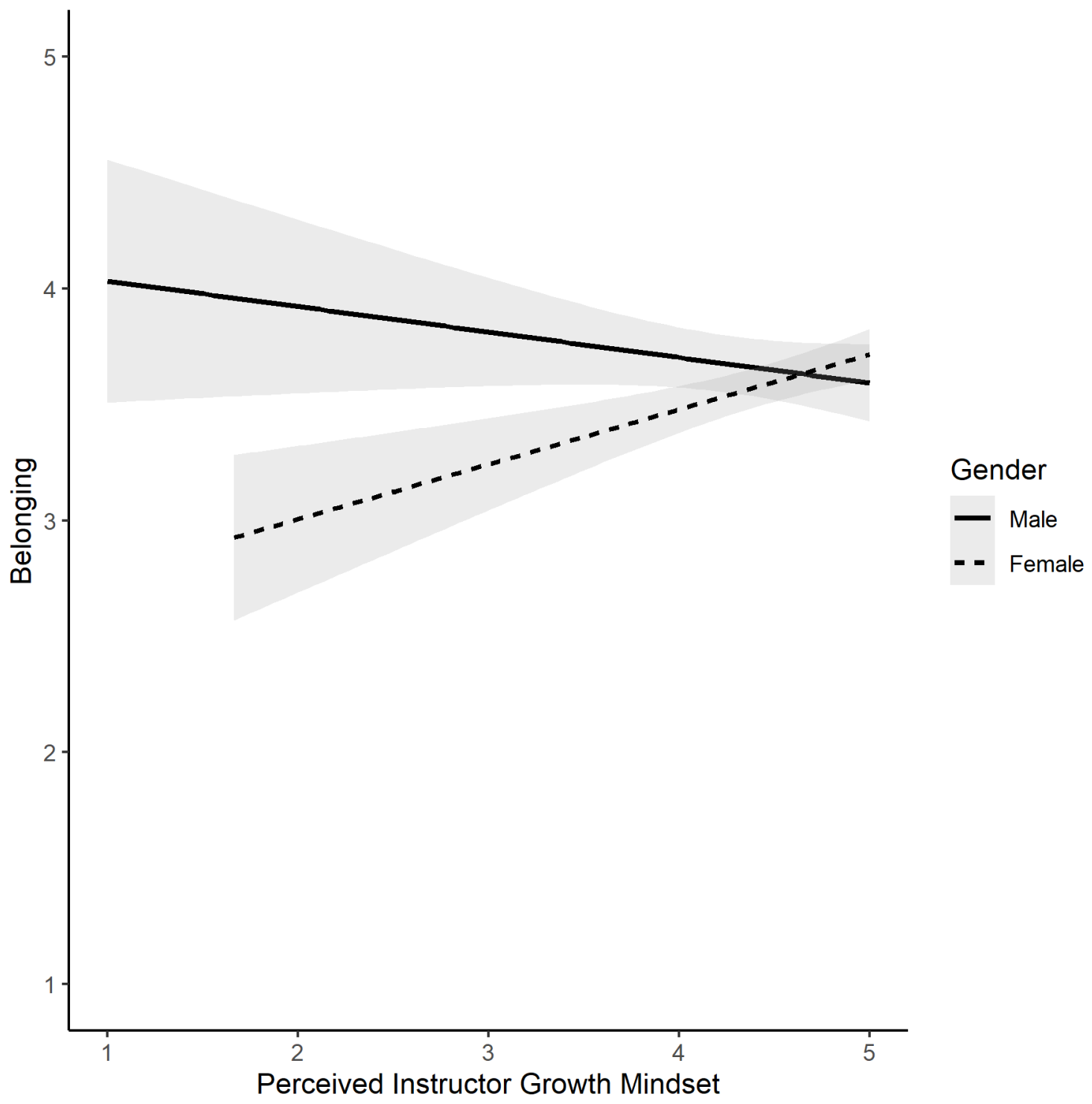

Fig. 7 Interaction between perceived instructor growth mindset and gender on belonging for participants in Study 2. Values represent raw scores. Shaded bands are 95\% confidence intervals 


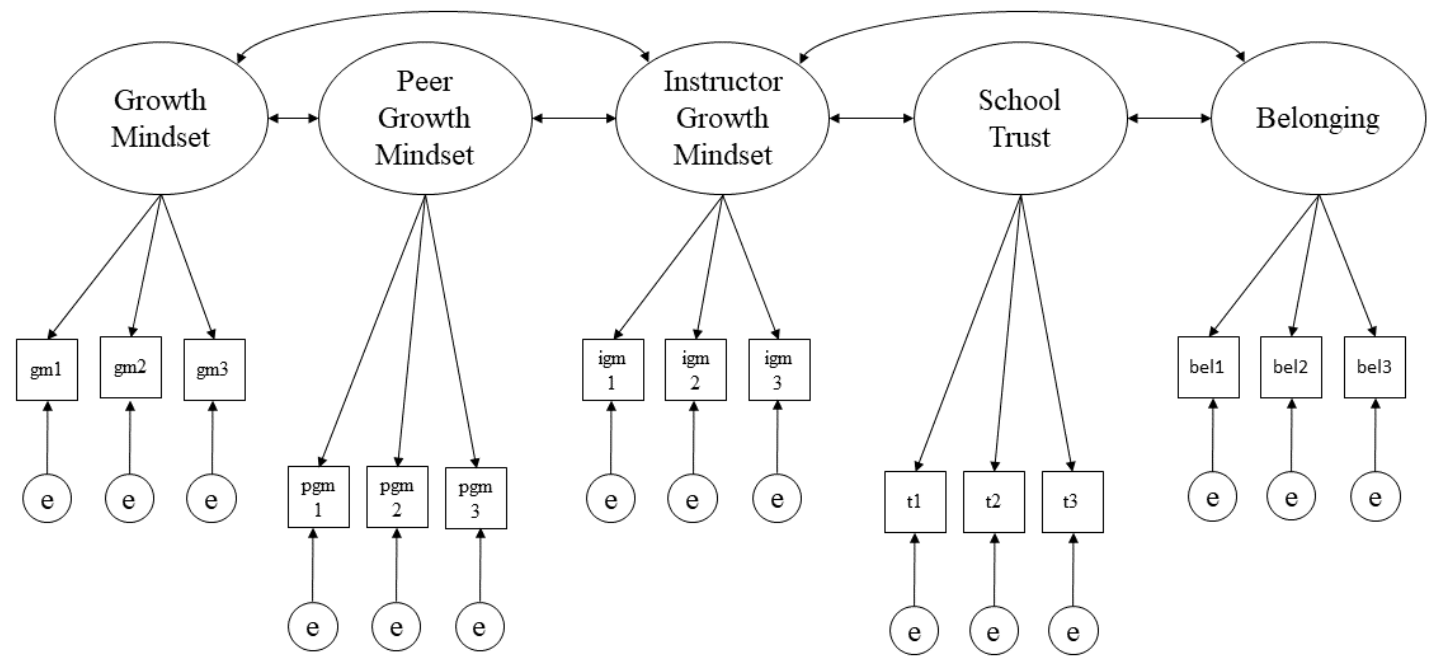

Fig. 8 Study 2 confirmatory factor analysis. Variances of the factors are fixed to 1. Parameter estimates are in Table 7. Comparative fit index $=0.98$, Tucker-Lewis Index $=0.97$, root mean square error of approximation $=0.033,95 \% \mathrm{CI}[0.028,0.039] . \mathrm{e}=$ error 


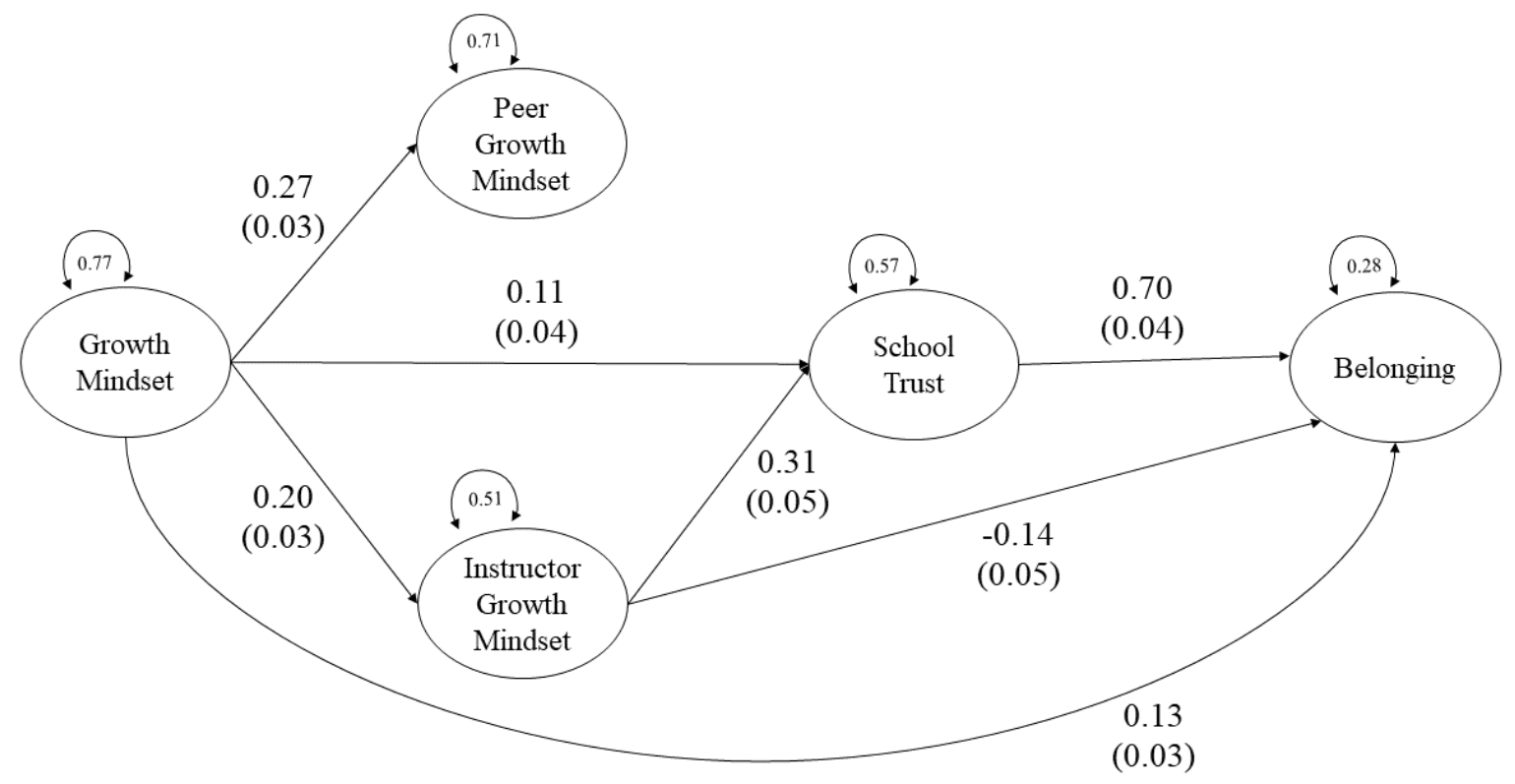

Fig. 9 Final empirical model after pruning and estimation for Study 2. Missing paths were nonsignificant and removed from the model for parsimony and to improve model fit (root mean square error of approximation). Path estimates are in standard deviation units (SEs in parentheses). All paths are significant $\mathrm{p}<.007$. The model controls for first generation status, low-income status, underrepresented racial-ethnic minority status, and gender by specifying paths from each covariate to each latent variable. $R^{2}=.55, \mathrm{CFI}=0.98, \mathrm{TLI}=0.98, \mathrm{RMSEA}=$ $0.023,95 \%$ CI [0.018, 0.027] 


\section{Appendix}

Table A1

Comparison of Measures Across Studies

\begin{tabular}{|c|c|c|}
\hline Construct & Study 1 Items & Study 2 Items \\
\hline \multirow[t]{4}{*}{$\begin{array}{l}\text { Growth } \\
\text { mindset }\end{array}$} & $\begin{array}{l}\text { Most people can learn to be good at } \\
\text { engineering. }\end{array}$ & $\begin{array}{l}\text { I have a certain amount of math ability, } \\
\text { and I can't really do much to change it. } \\
(\mathrm{R})\end{array}$ \\
\hline & $\begin{array}{l}\text { You have to be born with the ability to } \\
\text { be good at engineering. (R) }\end{array}$ & $\begin{array}{l}\text { My math ability is something about me } \\
\text { that I can't change very much. }(\mathrm{R})\end{array}$ \\
\hline & $\begin{array}{l}\text { Some people are good at engineering } \\
\text { and other people aren't. (R) }\end{array}$ & $\begin{array}{l}\text { Some people are good at math and } \\
\text { other people aren't. Being a "math } \\
\text { person" is not something you can } \\
\text { change. (R) }\end{array}$ \\
\hline & $\begin{array}{l}\text { Range: } 1=\text { strongly disagree, } 6= \\
\text { strongly agree }\end{array}$ & $\begin{array}{l}\text { Range: } 1=\text { strongly disagree, } 6= \\
\text { strongly agree }\end{array}$ \\
\hline \multirow[t]{4}{*}{$\begin{array}{l}\text { Perceived } \\
\text { peer } \\
\text { growth } \\
\text { mindset }\end{array}$} & $\begin{array}{l}\text { Most of my classmates believe that } \\
\text { you are either smart at engineering or } \\
\text { not. Being an engineering person is not } \\
\text { something that they think you can } \\
\text { change. (R) }\end{array}$ & $\begin{array}{l}\text { Most of my classmates believe that } \\
\text { you are either smart at math or not. } \\
\text { Being a math person is not something } \\
\text { you can change. (R) }\end{array}$ \\
\hline & $\begin{array}{l}\text { Most of my classmates believe that } \\
\text { you have a certain amount of } \\
\text { engineering ability and you can't do } \\
\text { much to change it. (R) }\end{array}$ & $\begin{array}{l}\text { Most of my classmates believe that } \\
\text { you have a certain amount of math } \\
\text { ability and you can't do much to } \\
\text { change it. (R) }\end{array}$ \\
\hline & $\begin{array}{l}\text { Most of my classmates think that your } \\
\text { engineering ability is something about } \\
\text { you that you can't change very much. } \\
\text { (R) }\end{array}$ & $\begin{array}{l}\text { Most of my classmates think that your } \\
\text { math ability is something about you } \\
\text { that you can't change very much. }(\mathrm{R})\end{array}$ \\
\hline & $\begin{array}{l}\text { Range: } 1=\text { strongly disagree, } 6= \\
\text { strongly agree }\end{array}$ & $\begin{array}{l}\text { Range: } 1=\text { strongly disagree, } 5= \\
\text { strongly agree }\end{array}$ \\
\hline $\begin{array}{l}\text { Perceived } \\
\text { instructor } \\
\text { growth } \\
\text { mindset }\end{array}$ & $\begin{array}{l}\text { My instructors believe that everybody } \\
\text { can be good at engineering. }\end{array}$ & $\begin{array}{l}\text { My math teacher seems to believe that } \\
\text { only a few students will understand the } \\
\text { hardest problems. (R) }\end{array}$ \\
\hline
\end{tabular}




\begin{tabular}{|c|c|c|}
\hline & $\begin{array}{l}\text { My instructors believe that only a few } \\
\text { students will understand the hardest } \\
\text { problems. (R) }\end{array}$ & $\begin{array}{l}\text { My math teacher seems to like you } \\
\text { better if you are good at math. (R) }\end{array}$ \\
\hline & $\begin{array}{l}\text { My instructors like students better } \\
\text { when they are good at engineering. (R) }\end{array}$ & $\begin{array}{l}\text { If you fall behind in my math class, my } \\
\text { math teacher does not slow down to let } \\
\text { you catch up. (R) }\end{array}$ \\
\hline & $\begin{array}{l}\text { My instructors believe that you are } \\
\text { either good at engineering or not. (R) }\end{array}$ & \\
\hline & $\begin{array}{l}\text { Range: } 1=\text { strongly disagree, } 6= \\
\text { strongly agree }\end{array}$ & $\begin{array}{l}\text { Range: } 1=\text { not at all, } 5=\text { extremely } \\
\text { true }\end{array}$ \\
\hline \multirow[t]{4}{*}{$\begin{array}{l}\text { School } \\
\text { trust }\end{array}$} & $\begin{array}{l}\text { I am treated fairly by faculty and staff } \\
\text { at [school]. }\end{array}$ & $\begin{array}{l}\text { How fairly are you treated by teachers } \\
\text { and other faculty/staff at [school]? }\end{array}$ \\
\hline & $\begin{array}{l}\text { Students in my racial and/or ethnic } \\
\text { group are treated fairly by faculty and } \\
\text { staff at [school]. }\end{array}$ & $\begin{array}{l}\text { To what degree are you treated with } \\
\text { respect by teachers and other } \\
\text { faculty/staff at [school]? }\end{array}$ \\
\hline & $\begin{array}{l}\text { Students of my socioeconomic } \\
\text { background are treated fairly by } \\
\text { faculty and staff at [school]. }\end{array}$ & $\begin{array}{l}\text { To what degree do your teachers give } \\
\text { you the grades you think you deserve? }\end{array}$ \\
\hline & $\begin{array}{l}\text { Range: } 1=\text { strongly disagree, } 7= \\
\text { strongly agree }\end{array}$ & $\begin{array}{l}\text { Range: } 1=\text { not at all, } 5=\text { an extreme } \\
\text { amount }\end{array}$ \\
\hline \multirow[t]{6}{*}{ Belonging } & I belong in Engineering at [school]. & $\begin{array}{l}\text { In this class, how much do you feel as } \\
\text { though you belong? }\end{array}$ \\
\hline & $\begin{array}{l}\text { I feel comfortable in Engineering at } \\
\text { [school]. }\end{array}$ & $\begin{array}{l}\text { How much do you feel like you matter } \\
\text { as a student in this class? }\end{array}$ \\
\hline & $\begin{array}{l}\text { Other people understand more than I } \\
\text { do about what is going on in } \\
\text { Engineering at [school]. (R) }\end{array}$ & $\begin{array}{l}\text { Overall, how comfortable do you feel } \\
\text { in this course as a member of the } \\
\text { student community? }\end{array}$ \\
\hline & $\begin{array}{l}\text { I think in the same way as do people } \\
\text { who do well in Engineering at } \\
\text { [school]. }\end{array}$ & \\
\hline & $\begin{array}{l}\text { It is a mystery to me how Engineering } \\
\text { at [school] works. (R) }\end{array}$ & \\
\hline & $\begin{array}{l}\text { I feel alienated from Engineering at } \\
\text { [school]. (R) }\end{array}$ & \\
\hline
\end{tabular}


I fit in well in Engineering at [school].

Compared with most other

Engineering students at [school], I am

similar to the kind of people who

succeed in Engineering.

Compared with most other students at

[school], I know how to do well in

Engineering.

Compared with most other

Engineering students at [school], I get

along well with people in Engineering.

$\begin{array}{ll}\text { Range: } 1=\text { strongly disagree, } 7= & \begin{array}{l}\text { Range: } 1=\text { not at all, } 5=\text { an extreme } \\ \text { amount }\end{array} \\ \text { strongly agree } & \end{array}$

Note. (R) indicates that the item was reverse-coded prior to analysis. 